Could the boom-bust in the eurozone periphery have been prevented?

Marcin Bielecki, Michał Brzoza-Brzezina, Marcin Kolasa, Krzysztof Makarski

Foundation of Admirers and Mavens of Economics Group for Research in Applied Economics 


\title{
Could the boom-bust in the eurozone periphery have been prevented?
}

\author{
Marcin Bielecki \\ University of Warsaw \\ NBP \\ Michal Brzoza-Brzezina \\ WSE \\ NBP
Marcin Kolasa
WSE
NBP
Krzysztof Makarski
FAME|GRAPE
WSE
NBP

\begin{abstract}
Boom-bust cycles in the eurozone periphery almost toppled the single currency and recent experience suggests that they may return soon. We check whether monetary or macroprudential policy could have prevented the periphery's violent boom and bust after the euro adoption. We estimate a DSGE model for the two euro area regions, core and periphery, and conduct a series of historical counterfactual experiments in which monetary and macroprudential policy follow optimized rules that use area-wide welfare as the criterion. We show that single monetary policy could have better stabilized output in both regions, but not the housing market or the periphery's trade balance. In contrast, region-specific macroprudential policy could have substantially smoothed the credit cycle in the periphery and reduced the build-up of external imbalances.
\end{abstract}

Keywords:

euro-area imbalances, monetary policy, macroprudential policy

JEL Classification

E32, E44, E58

Corresponding author

Krzysztof Makarski, k.makarski@grape.org.pl

Acknowledgements

The views expressed herein are those of the authors and not necessarily those of Narodowy Bank Polski. We would like to thank the participants of the NBP-NBU conference in Kyiv, Computing in Economics and Finance conference in Bordeaux, Dynare conference in Rome, European Economic Association Annual Meeting in Geneva, NBP-Deutsche Bundesbank Workshop in Kraków, Schumpeter Seminar at the Humboldt University in Berlin and seminar at DG-ECFIN in Brussels for useful comments.

Published by:

ISSN:
FAME | GRAPE

2544-2473

(c) with the authors, 2017
Foundation of Admirers and Mavens of Economics

ull. Mazowiecka 11/14

00-052 Warszaw

Poland
W | grape.org.pl

E | grape@grape.org.pl

$\Pi \mid$ GRAPE_ORG

FB | GRAPE.ORG

PH I +48799012202 


\section{Introduction}

The boom and bust cycle in the peripheral economies of the euro area is one of the most dramatic (but also most interesting) experiences in the recent economic history of developed countries. It started relatively innocently in the form of increasing demand and inflation pressure in selected countries of the single currency area. Over time, however, it evolved into a fully-fledged boom in the housing market, drew current accounts and international investment positions into deeply negative territories and, after property markets collapsed, triggered an economic, banking and fiscal crisis that almost toppled the single currency.

This episode has been extensively described in the literature (see e.g. Blanchard and Giavazzi 2002; Brzoza-Brzezina 2005; Honohan and Leddin 2006; Blanchard 2007; Fagan and Gaspar 2007; in't Veld et al. 2012; Chen et al. 2013). The main sources of the boom bust in the periphery were a sharp fall in its interest rates, possibly related to different equilibrium interest rates in this region and the Eurozone core (e.g. Belke and Klose, 2017), easy access to cross-border borrowing (e.g. Honohan and Leddin, 2006; Blanchard, 2007) and housing market developments (in’t Veld et al., 2012). More recent studies also highlight a much stronger responsiveness of the peripheral economies to area-wide shocks. This means that the business cycles within the euro area might be quite tightly synchronized (i.e. highly correlated), but their amplitudes are very different (De Grauwe and Ji, 2016; Belke et al. 2017).

We summarize these developments briefly in Figure 11, which plots the time series of output, residential investment, net exports, consumer price levels, housing loans and real house prices in the core (Austria, Belgium, Finland, France, Germany, Italy, Luxembourg, Netherlands) and in the periphery (Greece, Ireland, Portugal and Spain) of the euro area. Countries in the periphery experienced a housing market boom that was fueled by housing loans which - since partially financed in the core's interbank markets - contributed to current account deterioration. The boom was followed by a rapid decline in residential investment, house prices and housing loans. This decline resulted in a current account improvement. It is clear that the housing market boom-bust cycle, loss in competitiveness and large swing in economic activity were restricted to the periphery. While ultimately the imbalances have been mostly corrected, the associated pain (e.g. several years of very high unemployment rates) suggests that a policy intervention could have improved the outcome. Our main goal is to check whether policy, be it monetary or macroprudential, could have prevented such a scenario 1

We do not build on empty ground. The existing literature has already pointed to macroprudential policy as a possible solution to the problem of asymmetries in a monetary union.

\footnotetext{
${ }^{1}$ In principle, fiscal policy could also be used to stabilize the economy. However, given its limitations due to well-known political economy constraints and implementation lags, we leave it out of our study.
} 
Obviously, single monetary policy cannot deal with asymmetric shocks, especially if they affect a relatively small part of the single currency area (the GDP share of the affected peripheral members only slightly exceeds 15\%). However, a properly designed macroprudential policy could in principle complement monetary policy, as long as the asymmetric developments show up in areas where such policy can be effective. Since the boom-bust in the eurozone periphery was largely concentrated in the residential property market, the literature has mainly focused on the potential gains that can be achieved with adjustments in the macroprudential policy instruments related to housing mortgages.

Quint and Rabanal (2014) study the optimal mix of monetary and macroprudential policies in the euro area and find that the introduction of a rule affecting credit spreads would help reduce macroeconomic volatility and hence improve EMU-wide welfare. Brzoza-Brzezina et al. (2015) conclude that macroprudential policy using the loan-to-value (LTV) ratio as an instrument can substantially increase welfare in the euro area member countries affected by asymmetric shocks, provided that it is implemented at a national rather than union-wide level. Rubio (2014) develops this finding further and shows that the outcomes depend on the source of the observed heterogeneity between the member states, with potential welfare gains achievable when the asymmetries originate in the housing market. Our paper is also related to the vast literature that assesses macroprudential policy without explicitly modeling a monetary union (see e.g. Darracq-Pariés et al., 2011; Lambertini et al., 2013; Claessens, 2014). The closest paper to ours is Martin and Philippon (2017), who provide counterfactual simulations of the effects of macroprudential policy for selected Eurozone countries during the Great Recession. They find that macroprudential policy in the form of borrowing limits could have significantly reduced employment loss in the peripheral countries during the recession. However, their model features no housing sector nor an LTV limit controlled by the macroprudential authority, which is at the heart of our analysis.

While all these papers show a clear direction for future policies, they do not necessarily give a clear answer to the question stated in this paper's title. This is because their conclusions are based on stochastic simulations applied to a typical business cycle environment. However, as we confirm in our analysis, the series of shocks that hit the eurozone periphery was quite special in terms of sign and size. For this reason, we focus on the particular period when the boom developed and then turned into bust. Our results are thus based on historical counterfactual simulations for the period since the eurozone was created. Moreover, while designing such experiments it is crucial to account for potential structural heterogeneity between the core and peripheral countries as this may lead to different responses of key macroaggregates even in response to common shocks. Therefore, we base our conclusions on an estimated model, where the two regions of the euro area are not only hit by asymmetric shocks, but also are allowed to differ in average leverage as well as nominal and real rigidities. Indeed, we find that these structural differences make the periphery more prone 
to boom-bust cycles originating in the housing market.

Given the pronounced role of the housing market in the recent eurozone crisis, and our focus on counterfactual simulations with alternative monetary and macroprudential policy adjustments, our modeling strategy is relatively clear-cut. We construct a New Keynesian two-region DSGE model featuring a housing market, real and nominal frictions, and single monetary policy. The model is then estimated using macroeconomic data for the two areas of the eurozone. Our estimation confirms a pronounced role of housing markets in driving the boom in the periphery and its larger vulnerability.

Next, we conduct a series of counterfactual simulations. Our evaluation is based on a social welfare function. We begin by checking whether single monetary policy could have prevented the boom-bust. To this end, we generate counterfactual scenarios with monetary policy rule parameters optimized such that area-wide welfare is maximized. We show that such policy could have stabilized output in both regions of the monetary union quite well. However, its ability to affect housing loans or the trade balance is very limited. In contrast, macroprudential policy could have significantly smoothed the credit cycle in the periphery. It also appears as a promising way of limiting the build-up of external imbalances in this relatively more vulnerable region.

The rest of the paper is structured as follows. In Section 2 we present the model and in Section 3 we document its estimation and stochastic properties. Section 4 presents historical shock decompositions and discusses how differences in the economic structure make the periphery more prone to boom-bust cycles. In section 5 we describe the counterfactual simulations and we provide some robustness checks in Section 6. Section 7 concludes.

\section{Model description}

We construct a two-region New Keynesian DSGE model featuring a number of real and nominal rigidities in the spirit of Christiano et al. (2005) and Smets and Wouters (2007), as well as housing market frictions as in Iacoviello (2005). These two regions, called the core and periphery, form a monetary union, and are linked to each other via bilateral trade and financial flows, and common monetary policy. Both economies are populated by households, banks, firms, as well as fiscal, monetary and macroprudential authorities.

In each region there are two types of households: patient and impatient. Patient households are more forward-looking, i.e. they discount the future less heavily and hence save in equilibrium, holding positive stocks of capital, firm shares and deposits, while impatient households borrow in equilibrium. Banks collect deposits from patient households (potentially also from foreign ones) and then lend the funds to domestic impatient households. This channel serves as a proxy for international interbank markets and makes it possible for some of the credit boom in one region to be financed by savings from the rest of the monetary 
union 2 The extent of borrowing by impatient households is limited by collateral constraints. Specifically, the sum of principal and interest of a loan contract cannot exceed the expected value of borrowers' next-period housing stock, multiplied by a loan-to-value (LTV) ratio. The LTV ratio can be influenced by the macroprudential authority, and thus stands at the heart of our analysis.

Our modeling choice is related to the main application of the model, which will be counterfactual simulations assuming alternative policies. It is well known that in this case macroeconomic models are subject to the Lucas (1976) critique, which states that the model parameters may change when a different policy is applied. A response to this observation, also postulated by Lucas himself, is to construct models that are derived from microeconomic optimization problems, and this is what we do. While it may be argued that even DSGE models are not fully immune to the problem (see e.g. Chang et al., 2013), they nevertheless seem to be the best choice out of the available analytical tools. In what follows, variables and parameters without an asterisk refer to the periphery, while those with an asterisk refer to the core. Variables without time subscripts denote their respective steady state values. Since both regions have a symmetric structure, we describe the problems of agents in the periphery only.

\subsection{Households}

In each economy there are two types of households indexed by $\iota$ on a unit interval: patient $\iota \in P \equiv\left[0, \omega_{P}\right]$ and impatient $\left.\iota \in I \equiv\left(\omega_{P}, 1\right]\right]^{3}$ Hence, the measure of patient agents is $\omega_{P}$, while that of impatient households is $\omega_{I}=1-\omega_{P}$.

\section{Patient households}

Patient households discount the future with a factor $\beta_{P}$ and optimize by choosing consumption $c_{P, t}$, housing services $\chi_{P, t}$ and labor supply $n_{P, t}$. They set their own nominal wages $W_{P, t}$ in a monopolistically competitive environment and deposit savings $D_{P, t}$ in the banking sector, repaid with the nominal interest rate $R_{t}$ known in advance. We assume that patient households own all capital, as well as all shares of firms and banks in the economy. Thus, they receive rent $R_{k, t}$ from owned capital $]^{4} k_{P}$ and dividends $\Pi_{P, t}$. They also pay two lump

\footnotetext{
${ }^{2}$ Assuming that banks cannot lend to foreign households may seem as restrictive. However, according to the MFI balance sheets data published by the ECB, for the 12 countries that we consider in the paper, the share of loans granted to non-domestic eurozone households in April 2017 amounted to only $0.8 \%$, while the share of loans granted to non-domestic MFIs averaged $20 \%$.

${ }^{3}$ We employ the following notational convention: all variables denoted with a subscript $P$ or $I$ are expressed per patient or impatient household, respectively, while all other variables are expressed per all households. For example, $k$ denotes per capita capital and since only patient households own capital, capital per patient households is equal to $k_{P}=k / \omega_{P}$.

${ }^{4}$ We assume that the capital stock is fixed at the aggregate level.
} 
sum taxes, one as a fixed redistributive transfer to impatient households $\tau_{P}$ and the other to finance government consumption $\tau_{t}$.

A patient household $\iota$ maximizes its expected utility

$$
\begin{aligned}
U_{P, t}=E_{0}\left\{\sum_{t=0}^{\infty} \beta_{P}^{t}[\right. & \varepsilon_{u, t} \frac{\left(c_{P, t}(\iota)-\xi_{c} c_{P, t-1}\right)^{1-\sigma_{c}}}{1-\sigma_{c}} \\
& \left.\left.+\varepsilon_{u, t} \varepsilon_{\chi, t} A_{\chi} \nu\left(\chi_{P, t}\right)-A_{n} \frac{n_{P, t}(\iota)^{1+\sigma_{n}}}{1+\sigma_{n}}\right]\right\},
\end{aligned}
$$

subject to the budget constraint

$$
\begin{array}{r}
P_{t} c_{P, t}(\iota)+P_{\chi, t}\left[\chi_{P, t}(\iota)-\left(1-\delta_{\chi}\right) \chi_{P, t-1}(\iota)\right]+D_{P, t}(\iota)+\tau_{P}+\tau_{t} \\
\leq W_{P, t}(\iota) n_{P, t}(\iota)+R_{k, t} k_{P}(\iota)+R_{t-1} D_{P, t-1}(\iota)+\Pi_{P, t}(\iota),
\end{array}
$$

where $\xi_{c}$ measures the degree of external habit persistence in consumption, $A_{\chi}$ and $A_{n}$ are the weights of housing and labor in utility, $\sigma_{c}$ denotes the inverse of intertemporal elasticity of substitution in consumption, $\sigma_{n}$ is the inverse Frisch elasticity of labor supply, and $\delta_{\chi}$ is the rate of housing depreciation. There are two preference shocks - an intertemporal

preference shock $\varepsilon_{u, t}$ and a housing preference shock $\varepsilon_{\chi, t}$, both following independent $\operatorname{AR}(1)$ processes. Finally, prices of consumption and housing are denoted as $P_{t}$ and $P_{\chi, t}$. In what follows, prices written with lower case letters are expressed in real terms, relative to the CPI index $P_{t}$.

While estimating and simulating the model, following Justiniano et al. (2015) we assume that the utility of the housing services flow $\nu\left(\chi_{P, t}\right)$ is such that it implies a rigid housing demand of patient households at the level $\chi_{P}$. This assumption implies that there is no reallocation of houses across the two types of households, which can be motivated by some housing market segmentation, as argued by Landvoigt et al. (2015). It is also consistent with the argument by Geanakoplos (2010) that prices are determined by marginal agents.

\section{Impatient households}

Impatient households discount the future with the factor $\beta_{I}<\beta_{P}$ and optimize by choosing consumption $c_{I, t}$, housing services $\chi_{I, t}$ and labor supply $n_{I, t}$. They set their nominal wages $W_{I, t}$ and acquire loans $L_{I, t}$ from the banking sector, charged with the nominal interest rate $R_{L, t}$ known in advance. Access to credit is constrained by the value of collateral. While impatient households pay a tax financing government spending just as patient households, they also receive a redistributive lump sum transfer $\tau_{I}$. 
An impatient household $\iota$ maximizes its expected utility

$$
\begin{aligned}
U_{I, t}=E_{0}\left\{\sum_{t=0}^{\infty} \beta_{I}^{t}[\right. & \varepsilon_{u, t} \frac{\left(c_{I, t}(\iota)-\xi_{c} c_{I, t-1}\right)^{1-\sigma_{c}}}{1-\sigma_{c}} \\
& \left.\left.\quad+\varepsilon_{u, t} \varepsilon_{\chi, t} A_{\chi} \frac{\left(\chi_{I, t}(\iota)-\xi_{\chi} \chi_{I, t-1}\right)^{1-\sigma_{\chi}}}{1-\sigma_{\chi}}-A_{n} \frac{n_{I, t}(\iota)^{1+\sigma_{n}}}{1+\sigma_{n}}\right]\right\},
\end{aligned}
$$

where $\xi_{\chi}$ and $\sigma_{\chi}$ denote the degree of external habit persistence and the inverse of intertemporal elasticity of substitution in housing, respectively. This optimization is subject to the budget constraint

$$
\begin{array}{r}
P_{t} c_{I, t}(\iota)+P_{\chi, t}\left[\chi_{I, t}(\iota)-\left(1-\delta_{\chi}\right) \chi_{I, t-1}(\iota)\right]+R_{L, t-1} L_{I, t-1}(\iota)+\tau_{t} \\
\leq W_{I, t}(\iota) n_{I, t}(\iota)+L_{I, t}(\iota)+\tau_{I}
\end{array}
$$

and the collateral constraint on credit

$$
R_{L, t} L_{I, t}(\iota) \leq m_{\chi, t} E_{t}\left\{P_{\chi, t+1}\right\}\left(1-\delta_{\chi}\right) \chi_{I, t}(\iota)
$$

where $m_{\chi, t}$ is the LTV ratio set by the macroprudential authority.

\section{Labor market}

The differentiated labor services of patient and impatient households are purchased by competitive aggregators who transform them to standardized labour services $n_{t}$ using the following technology

$$
n_{t}=\left[\omega_{P}^{\frac{1}{\phi_{n}}} n_{P, t}^{\frac{\phi_{n}-1}{\phi_{n}}}+\omega_{I}^{\frac{1}{\phi_{n}}} n_{I, t}^{\frac{\phi_{n}-1}{\phi_{n}}}\right]^{\frac{\phi_{n}}{\phi_{n}-1}}
$$

where

$$
n_{P, t}=\left[\frac{1}{\omega_{P}} \int_{0}^{\omega_{P}} n_{P, t}(\iota)^{\frac{1}{\mu_{w}}} \mathrm{~d} \iota\right]^{\mu_{w}} \quad \text { and } \quad n_{I, t}=\left[\frac{1}{\omega_{I}} \int_{0}^{\omega_{I}} n_{I, t}(\iota)^{\frac{1}{\mu_{w}}} \mathrm{~d} \iota\right]^{\mu_{w}} .
$$

In the formulas above, $\phi_{n}$ measures the elasticity of substitution between patient and impatient labour, and $\mu_{w}$ denotes households' markup over the competitive wage level.

Nominal wages set by the households are sticky as in the Calvo scheme, and within each period only a fraction $1-\theta_{w}$ of them receives a signal to reoptimize. Others update their wages according to $\pi_{\zeta_{w}, t}=\zeta_{w} \pi_{t-1}+\left(1-\zeta_{w}\right) \pi$, where $\pi_{t} \equiv P_{t} / P_{t-1}$ is CPI inflation, $\pi$ is its

steady state level, and $\zeta_{w}$ is the weight of past inflation in the wage indexing scheme. We 
assume that households share risk perfectly within each type, either through large families or through access to complete markets for Arrow-Debreu securities. Thus, wage stickiness does not translate into consumption and housing stock heterogeneity.

\subsection{Producers}

There are three types of producers in the economy - final goods, housing and intermediate goods producers. All of them are owned by patient households. The first two types of producers operate in perfectly competitive markets and use only intermediate goods as inputs, which in turn are produced by monopolistically competitive sector that employs capital and labor.

\section{Final goods producers}

Final goods producers purchase domestic $f_{H, t}$ and foreign $f_{F, t}$ intermediate goods varieties and produce a homogeneous final good according to the following technology

$$
f_{t}=\left[\eta_{H}^{\frac{1}{\phi_{f}}} f_{H, t}^{\frac{\phi_{f}-1}{\phi_{f}}}+\left(1-\eta_{H}\right)^{\frac{1}{\phi_{f}}} f_{F, t}^{\frac{\phi_{f}-1}{\phi_{f}}}\right]^{\frac{\phi_{f}}{\phi_{f}-1}}
$$

where

$$
f_{H, t}=\left[\int_{0}^{1} f_{H, t}(i)^{\frac{1}{\mu_{t}}} \mathrm{~d} i\right]^{\mu_{t}} \quad \text { and } \quad f_{F, t}=\left[\int_{0}^{1} f_{F, t}(i)^{\frac{1}{\mu_{t}}} \mathrm{~d} i\right]^{\mu_{t}} .
$$

In the above formulas, $\eta_{H}$ reflects the home bias in consumption, $\phi_{f}$ is the elasticity of substitution between domestic and foreign intermediates, and $\mu_{t}$ is an $\mathrm{AR}(1)$ markup shock.

\section{Housing producers}

Aggregate housing stock $\chi_{t}$ in the economy evolves according to

$$
\chi_{t}=\left(1-\delta_{\chi}\right) \chi_{t-1}+\varepsilon_{i \chi, t}\left[1-S_{\chi}\left(\frac{i_{\chi, t}}{i_{\chi, t-1}}\right)\right] i_{\chi, t},
$$

where $\varepsilon_{i \chi, t}$ is an $\mathrm{AR}(1)$ investment technology shock, $i_{\chi, t}$ denotes investment in housing and

$$
S_{\chi}\left(\frac{i_{\chi, t}}{i_{\chi, t-1}}\right)=\frac{\kappa_{\chi}}{2}\left(\frac{i_{\chi, t}}{i_{\chi, t-1}}-1\right)^{2}
$$

is the investment adjustment cost function, with $\kappa_{\chi}>0$.

Investment results from optimal choices made by perfectly competitive housing producers who acquire domestic intermediate goods and combine them into homogeneous housing 
investment good

$$
i_{\chi, t}=\left[\int_{0}^{1} i_{\chi, t}(i)^{\frac{1}{\mu_{t}}} \mathrm{~d} i\right]^{\mu_{t}}
$$

\section{Intermediate goods producers}

Monopolistically competitive intermediate goods producers indexed by $i$ employ capital and labor to produce output according to the Cobb-Douglas production technology, with $\varepsilon_{z, t}$ denoting an $\mathrm{AR}(1)$ productivity shock and $\alpha$ denoting the capital share of output. Output is supplied to domestic final goods producers, foreign final goods producers, and domestic housing producers.

$$
f_{H, t}(i)+\frac{1-\omega}{\omega} f_{H, t}^{*}(i)+i_{\chi, t}(i)=\varepsilon_{z, t} k(i)^{\alpha} n_{t}(i)^{1-\alpha} .
$$

All firms set their prices independently for the domestic and foreign markets according to the Calvo scheme. Both markets have their own price reoptimization probabilities, denoted respectively by $1-\theta_{H}$ and $1-\theta_{F}$. While not being allowed to reoptimize, firms update prices according to $\pi_{\zeta H, t}=\zeta_{H} \pi_{t-1}+\left(1-\zeta_{H}\right) \pi$ in the domestic market and $\pi_{\zeta F, t}^{*}=\zeta_{F} \pi_{t-1}^{*}+$ $\left(1-\zeta_{F}\right) \pi^{*}$ in the foreign market, with $\zeta_{\mathrm{S}}$ controlling the weights of past inflation in the indexation schemes.

\subsection{Closing the model}

\section{GDP, net exports and balance of payments}

Real gross domestic product at market prices $y_{t}$ is defined as the sum of private and government consumption, investment in housing and net exports $n x_{t}$,

$$
y_{t}=f_{t}+p_{i \chi, t} i_{\chi, t}+n x_{t}
$$

where

$$
n x_{t}=\frac{1-\omega}{\omega} q_{t} p_{H, t}^{*} f_{H, t}^{*}-p_{F, t} f_{F, t}+\varepsilon_{\text {row }, t} .
$$

In the equation above, $q_{t}=P_{t}^{*} / P_{t}$ stands for the real exchange rate and $\varepsilon_{\text {row }, t}$ is a net exports shock from the rest of the world, which we assume to affect only the periphery.

Real net foreign debt $\tilde{d}_{t}$ is given by

$$
\tilde{d}_{t}=-n x_{t}+\frac{R_{t-1}}{\pi_{t}} \tilde{d}_{t-1},
$$


where $\varrho_{t} \equiv 1+\xi\left[\exp \left(\tilde{d}_{t} / y_{t}\right)-1\right] \varepsilon_{\xi, t}$ is a risk premium factor that depends on the international investment position of a country, with $\xi>0$. A risk premium shock $\varepsilon_{\xi, t}$ is included to account for the pre-euro interest rate differential between the core and periphery.

\section{Banking sector}

Banks collect deposits from patient households (potentially also from foreign ones) and then lend the funds to impatient households, setting the lending rate in a monopolistically competitive manner.

A $j$-th bank maximizes profits, evaluated using the marginal utility of patient households' future consumption

$$
E_{t}\left\{\beta_{P} \frac{u_{P, t+1}^{c}}{P_{t+1}}\left[R_{L, t}(j) L_{t}(j)-R_{t} D_{t}(j)-\varrho_{t} R_{t}^{*} D_{t}^{*}(j)\right]\right\},
$$

subject to

$$
L_{t}(j)=D_{t}(j)+D_{t}^{*}(j),
$$

where $L_{t}(j), D_{t}(j)$ and $D^{*}(j)$ denote $j$-th bank's real loans, domestic deposits and foreign deposits, respectively.

The differentiated loans are aggregated according to the following formula

$$
\omega_{I} L_{I, t}=\left[\int_{0}^{1} L_{t}(j)^{\frac{1}{\mu_{L, t}}} \mathrm{~d} j\right]^{\mu_{L, t}},
$$

where $\mu_{L, t}$ is the stochastic $\mathrm{AR}(1)$ markup for loans. The above considerations imply that all banks charge the same lending rate $R_{L, t}=\mu_{L, t} R_{t}$, and that the following uncovered interest rate parity holds $R_{t}=\varrho_{t} R_{t}^{*}$.

\section{Fiscal and monetary policy}

The fiscal authority collects lump sum taxes $\tau_{t}$ to finance government consumption $g_{t}$, which on average amounts to $\bar{g}$ share of GDP. For simplicity we assume that the government budget is balanced in each period. Fluctuations in government spending are modeled as an exogenous $\operatorname{AR}(1)$ process $\varepsilon_{g, t}$ so that

$$
\tau_{t}=g_{t}=\bar{g} \cdot y_{t} \cdot \varepsilon_{g, t}
$$

The monetary authority sets the short term interest rate reacting to union-wide variables according to a Taylor-like formula

$$
\frac{R_{t}^{*}}{R^{*}}=\left(\frac{R_{t-1}^{*}}{R^{*}}\right)^{\gamma_{R}^{*}}\left[\left(\frac{\tilde{\pi}_{t}^{*}}{\tilde{\pi}^{*}}\right)^{\gamma_{\pi}^{*}}\left(\frac{\tilde{y}_{t}^{*}}{\tilde{y}^{*}}\right)^{\gamma_{y}^{*}}\right]^{1-\gamma_{R}^{*}} \varepsilon_{R, t}^{*}
$$


where $\gamma_{R}^{*}$ controls the degree of interest rate smoothing, $\varepsilon_{R, t}^{*}$ is a white noise monetary policy shock, while $\gamma_{\pi}^{*}$ and $\gamma_{y}^{*}$ control the strength of policy rate response to area-wide inflation and output

$$
\tilde{\pi}_{t}^{*} \equiv\left(\pi_{t}\right)^{\omega}\left(\pi_{t}^{*}\right)^{1-\omega} \quad \text { and } \quad \tilde{y}_{t}^{*} \equiv \omega y_{t}+(1-\omega) y_{t}^{*}
$$

\section{Macroprudential policy}

The macroprudential authority may set the LTV ratio according to

$$
\frac{m_{\chi, t}}{m_{\chi}}=\left(\frac{l_{t}}{l}\right)^{\gamma_{m l}}\left(\frac{p_{\chi, t}}{p_{\chi}}\right)^{\gamma_{m p}} .
$$

In the formula above, $m_{\chi}$ is the steady state LTV ratio and parameters $\gamma_{m l}$ and $\gamma_{m p}$ determine the strength of reaction to deviations of, respectively, real loans $l_{t}$ and real house prices $p_{\chi, t}$ from their steady state values.

\section{Market clearing}

We impose a standard set of market clearing conditions. Housing market clearing implies

$$
\omega_{P} \chi_{P, t}+\omega_{I} \chi_{I, t}=\chi_{t}
$$

Consumption of both types of households together with government consumption must be equal to final goods supply

$$
\omega_{P} c_{P, t}+\omega_{I} c_{I, t}=c_{t} \text { and } c_{t}+g_{t}=f_{t}
$$

Finally, capital and labor markets clear

$$
\int_{0}^{1} k_{t}(i) \mathrm{d} i=\omega_{P} k_{P} \quad \text { and } \quad \int_{0}^{1} n_{t}(i) \mathrm{d} i=n_{t}
$$

\section{Calibration and estimation}

For the purpose of estimation we define the two regions of the euro area as follows: the periphery consisting of Greece, Ireland, Portugal and Spain, and the core consisting of Austria, Belgium, Finland, France, Germany, Italy, Luxembourg and the Netherlands. Obviously, these groups are not perfectly homogeneous. What makes the periphery countries similar are large and persistent current account deficits that can be interpreted as evidence of strong demand pressures, housing market booms (except for Portugal) and loss of competitiveness in the years after the euro adoption. In all countries the boom turned into bust after the 
outburst of the global financial crisis. These boom-bust patterns are crucial for our analysis, but it should be noted that our classification is also in line with the core-periphery division found by Bayoumi and Eichengreen (1992) and Campos and Macchiarelli (2016) on the basis of business cycle correlations. ${ }^{5}$

\subsection{Calibration}

As it is standard in the literature, we calibrate most of the parameters affecting the model's steady state equilibrium ${ }^{6}$ We use as targets the averages of key macroeconomic proportions observed in the data over the period 1995-2014. The values of all calibrated parameters are presented in Table 1 and the targeted steady state ratios are reported in Table 2.

Our model features two regions: the periphery consisting of Greece, Ireland, Portugal and Spain, and the core consisting of Austria, Belgium, Finland, France, Germany, Italy, Luxembourg and the Netherlands. We calibrate the size of the periphery to $16.8 \%$, which corresponds to the average share of this region in the euro area GDP for the period covered by our analysis. We set the share of home-made goods in the periphery's consumption basket at 0.7, which is consistent with the estimates of Bussiere et al. (2013) for the euro area member states. Adjusting this number for the relative size of the two regions leads to the corresponding share in the core of 0.06. The share of impatient households is calibrated at 0.675 in the periphery and at 0.5 in the core, which allows us to match the debt to annual GDP ratio in these two regions of 0.70 and 0.52 , respectively.

Since in the data we neither see strong evidence of long-term differences between the core and periphery as regards the remaining steady state ratios, nor the observed heterogeneity is important for our main results, we keep the rest of our calibration symmetric across the two regions. The share of government spending in GDP is fixed at 0.25. We calibrate the weight of housing and labor in utility function using the following formulas $A_{\chi}=1.67 \cdot\left(1-\xi_{\chi}\right)^{\sigma_{\chi}}\left(1-\xi_{c}\right)^{\sigma_{c}}$ and $A_{n}=35.1 \cdot\left(1-\xi_{c}\right)^{-\sigma_{c}}$. This guarantees that, irrespective of the degree of habit formation that we estimate, the housing wealth to GDP ratio equals 1.78 and the hours worked equal 0.33. As in Coenen et al. (2008), we assume that the elasticity of substitution between domestic and imported goods equals 1.5, and the elasticity of substitution between labor of patient and impatient households equals 6 . In the steady state, markups in the labor and product markets are all set to $20 \%$, and the capital share in output is fixed at 0.3 .

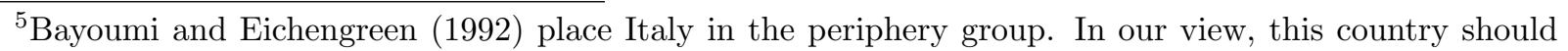
be included in the core group as it did not face a boom-bust scenario after the euro adoption. Nevertheless, we conduct a robustness check where Italy is counted as a peripheral country and our main findings remain unaffected.

${ }^{6}$ While solving for the steady state we fix the housing stock owned by patient households $\chi_{P}$ to 8.24 and $\chi_{P}^{*}$ to 7.31 , which are the values that would be obtained if we assumed that their housing utility is of the same form as that characterizing impatient agents, i.e. $\nu\left(\chi_{P, t}\right)=\frac{\left(\chi_{P, t}(\iota)-\xi_{\chi} \chi_{P, t-1}\right)^{1-\sigma_{\chi}}}{1-\sigma_{\chi}}$.
} 
We set the discount factor applied by patient households to 0.998 to match the annual real interest rate in the euro area of $0.8 \%$. The discount factor of impatient agents is calibrated at 0.983 to match the share of residential investment in GDP of $7 \%$. As it is standard in the literature, we fix the inverse of the intertemporal elasticity of substitution in consumption and housing, as well as the inverse of the Frisch elasticity for labor supply at 2. We assume that each quarter $1 \%$ of housing depreciates. We set the LTV ratio to a conventional level of 0.75. Transfers from patient to impatient households are calibrated at 0.25 so that the steady state per capita consumption of impatient agents equals $0.7-0.8$ of per capita consumption of patient agents, similarly to Coenen et al. (2008). Loan markups are calibrated at 0.0047 to match annual spreads in the euro area of 0.019 . The steady state inflation rate is set to $2 \%$ annually.

\subsection{Data and prior assumptions}

We estimate the model using time series covering the period 1995q1-2012q3, giving us $T=71$ quarterly observations.7 The data we use in simulations run to 2015q1, but we decided to exclude the period during which the zero lower bound (ZLB) constraint on the eurozone's nominal interest rates was binding. 8

We use the following seven pairs of data series for the core and periphery: real GDP less non-residential investment, real private consumption, real residential investment, real housing loans, real house prices, HICP inflation and interest on housing loans. We also treat as observable the euro money market rate and its pre-euro value in the periphery. $9^{9}$ as well as the periphery's net exports relative to GDP. This gives us in total seventeen observed time series.

The national accounts series, HICP inflation and money market rates come from Eurostat. House prices are defined as residential property prices of new and existing houses and flats and come from the BIS Long-term series on nominal residential property prices and ECB SDW. Housing loans are defined as outstanding amounts of lending for house purchase and were taken from the ECB SDW. The lending interest rate corresponds to the quarterly interest on housing loans to households taken from the ECB SDW. All variables are seasonally adjusted. House prices and lending for house purchase are expressed in real terms using HICP. The

\footnotetext{
${ }^{7}$ Since the HICP index is not available before 1996, our inflation and real house price series start in 1996q1. Data on housing loans and interest on housing loans are available from 1997q3. While estimating the model we use the Kalman filter to fill in these missing observations.

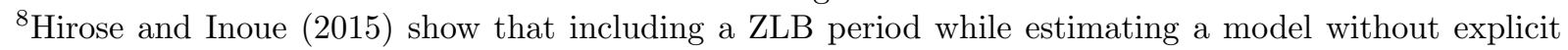
modeling of this constraint may lead to biased parameter estimates. This bias increases with the duration of the ZLB period.

${ }^{9}$ The difference between these two money market rates is non-zero only before the eurozone creation. The reason for including data on this pre-euro interest spread in estimation is to capture the effects of interest rate convergence among the prospective euro area members before 1999. in't Veld et al. (2012) identify this process as an important driver of the lending boom in the periphery.
} 
national accounts series and real loans were divided by population size. Before estimation, GDP, its components, real house prices and loans were transformed into growth rates and subsequently demeaned.

To estimate the model we use Bayesian methods. The prior and posterior distribution characteristics for structural parameters and shocks are presented, respectively, in Tables 3 and 4. Our priors are based on the previous literature. We set the prior mean for the Calvo probabilities at 0.75 , which is consistent with the empirical estimates of average price

duration reported by Álvarez et al. (2006). The prior distribution for indexation parameters and habits are all centered around the standard value of 0.5 . We set the prior mean of the investment adjustment cost parameter to 30 , which is close to the value used in BrzozaBrzezina et al. (2015). The prior mean of the debt elasticity of risk premium is set to 0.005 , which is a value that stabilizes foreign debt at zero without affecting much the short term model dynamics.

The prior means for the monetary policy rule are set to standard values used in the literature. For lack of evidence on the monetary policy bias towards one of the regions, while estimating our model we use population weights for aggregates defined by equations (21). Since macroprudential policy was not used in a systematic fashion in the euro area during the period covered by our sample, the feedback parameters showing up in equation 22) are both set to zero so that the LTV ratio is constant. All of these monetary and macroprudential policy parameters will be subject to optimization while constructing our counterfactual simulations described later in the text.

Our model is driven by seventeen stochastic shocks. These include the pairs of productivity, time preference, housing preference, price, wage and loan markups, as well as government expenditure shocks in the core and periphery. Additionally, we have a common monetary policy shock, a shock to the periphery's net exports and a risk premium shock accounting for the interest rate differential between the two regions prior to euro creation. All shocks are modeled as first-order autoregressive processes, except for the monetary policy shock that is assumed to be white noise.

We set the prior means of shock inertia to 0.7 , with fairly large standard deviations. The prior distributions of shock volatilities are centered around 0.01. A smaller prior mean of 0.001 is assumed for shocks affecting the interest rates (i.e. monetary policy, loan markup and risk premium shocks), consistently with the previous literature.

\subsection{Estimation results}

We estimate the model using Bayesian methods as described i.a. by An and Schorfheide (2007) with Dynare version 4.4.3. The posterior mode in the first pass is obtained with the 
CMA-ES procedure ${ }^{10}$ while the second pass uses Christopher Sims' optimization routine. We next run the Metropolis-Hastings algorithm with two blocks, each consisting of 250,000 replications. Convergence was confirmed by a set of diagnostic tests proposed by Brooks and Gelman (1998). Finally, the posterior distributions are approximated using the second half of the draws.

As can be seen from Tables 3 and 4 , our dataset is informative about all of the estimated parameters, except for habits in housing, price indexation in imports, and feedback parameters in the monetary policy rule. The posterior modes are broadly consistent with earlier estimates in the literature obtained for the euro area. We find some evidence of structural heterogeneity between the two regions of the monetary union, with the degree of nominal and real rigidities usually higher in the periphery. This is particularly true for the residential investment adjustment cost and, to a lesser extent, habits in consumption and wage stickiness. As regards the estimates of processes driving stochastic shocks, they are usually more inertial and more volatile in the periphery, consistently with larger business cycles observed in that region. 11

In Tables 5 and 6 we present the forecast error variance decompositions for the core and the periphery implied by our model and evaluated at the posterior mean of the estimated parameters. For the sake of clarity, we collect the shocks into groups. It is clear that local housing market shocks are more important in the periphery, where they account for more than a half of fluctuations in GDP and its components, as well as in housing loans and house prices. The contribution of these shocks in the core is also substantial, but smaller than that of other domestic demand and supply shocks, except for residential investment and house prices. As expected, the periphery is much more influenced by shocks originating from abroad than the core. In particular, foreign shocks drive most of the observed fluctuations in the periphery's cost of housing loans.

\footnotetext{
10 Andreasen (2010) shows that the CMA-ES algorithm outperforms Simulated Annealing and Nelder-Mead algorithms in finding the 'true' parameters of DSGE models with many estimated parameters.

${ }^{11}$ We want to add a caveat here. The estimation is based on a model that is log-linearized around the steady state, but the estimated standard deviations of some shocks are substantial. The main advantage of our approach comparing to the one based on global solution methods is that we are able to estimate a fairly rich model, with a large number of state variables. We believe that, given the questions we ask, the benefits of having a detailed framework outweigh the possible losses related to the inaccuracy introduced by the linear approximation.
} 


\section{Inspecting heterogeneity between the core and pe- riphery}

\subsection{Historical shock decomposition}

Before we conduct our counterfactual simulations, we analyze the role of exogenous shocks, which in a DSGE model have an economic interpretation, in driving key macroeconomic variables in the periphery. Figure 4 documents the historical shock decomposition of this region's GDP, net exports, housing loans, house prices, residential investment and the real exchange rate. It is clear that housing market shocks were the main drivers of imbalances observed in the periphery's housing market over the analyzed period. The dominance of these shocks is especially pronounced in the case of housing loans, house prices and residential investment, where the impact of other shocks is almost negligible. Before the residential property market collapsed in 2007, the housing demand shock was highly positive, driving all four variables away from the long-run equilibrium. Housing supply shocks acted as a countervailing force, dampening investment and GDP, and boosting house prices. After 2007, housing demand waned, which might be tentatively associated with the flight of foreign property investors from the peripheral housing market towards safer assets. The contribution of past housing demand shocks still was visible in the level of outstanding loans, but was steadily diminishing as fewer new loans were granted. In this period, housing supply shocks were slowing down the collapse of house prices, which moderated the effects of the collateral losses. A different picture emerges for the real exchange rate, which can be interpreted as a measure of price competitiveness, and which has been mainly driven by supply-side factors, i.e. productivity and markup shocks.

The supply side factors also contributed significantly to the deterioration in the periphery's trade balance from 1999 till 2005, with wage stickiness playing an important role in the transmission of these shocks, and were also important drivers of fluctuations in this region's output. However, for these two variables housing market shocks seem to be more important. A non-negligible role is also played by foreign (i.e. core) developments. They helped dampen the cyclical fluctuations in the periphery's GDP while deepening the current account deterioration. Consistently with the previous literature, the build-up of external imbalances in the periphery was also largely driven by the pre-euro interest rate convergence.

Other shocks were of relatively lesser importance for the periphery during the analyzed period. Non-housing domestic demand shocks amplified the cycle in GDP around its peak and postponed the current account reversal. As from 2012, these shocks contributed to the stagnation in output, which mainly reflected the applied fiscal retrenchment. Monetary

policy shocks reduced the slump in economic activity until the interest rate hit the zero lower bound. 


\subsection{Is the periphery more vulnerable to housing booms?}

We have seen in Figure 1 that while the periphery experienced a massive boom-bust cycle, the macroeconomic developments in the core over the same period did not significantly deviate from a typical business cycle. As we have already mentioned, this reflects to a large extent the fact that shocks hitting the periphery were much larger and more persistent. However, our estimation also shows that not only shock properties, but also some of the structural parameters differ significantly across the two regions, pointing to stronger nominal and real rigidities in the periphery. A natural way of evaluating whether this structural heterogeneity makes the periphery more vulnerable than the core is to compare the reactions of these two economic areas to common disturbances.

As an illustration we use a common housing demand shock, which we choose because of its dominant role in driving the boom-bust cycle in the periphery documented above. In this exercise, the inertia of this shock is assumed to be the same in the two regions and equal to that estimated for the core. The impulse responses are plotted in Figure 5. If structural parameters were the same in the core and periphery, we should see no difference between the two reactions. This is clearly not the case. Since house supply is more rigid in the periphery (housing investment responds more sluggishly), house prices in this region increase by much more than in the core. As credit must be secured with housing collateral, its expansion in the periphery is initially weaker, but after a year markedly stronger than in the core.

These differences in the propagation through the housing and credit markets have aggregate demand consequences. As a result, GDP in the periphery increases more than in the core. The current account balance deteriorates, which means that the credit boom in the periphery is partly financed by borrowing from the core. Overall, it is clear that even if both regions of the euro area were hit by the same housing preference shocks, the reaction of output, house prices, credit and external balance would be stronger in the periphery because of the differences in economic structure, and the housing sector in particular. This finding is consistent with empirical evidence presented by De Grauwe and Ji (2016) or Belke et al. (2017), who show that even a common cycle can lead to large asymmetries within the euro area.

\section{Counterfactual policy experiments}

Our model is now ready to conduct a series of simulations that are aimed to answer the question whether monetary or macroprudential policy could have, to a substantial degree, prevented the boom-bust in the eurozone periphery. We first look at union-wide monetary policy, taking as given the fact that countries form a monetary union. Hence, the question what would have happened under independent monetary regimes is not asked in this study. 
Next we look at country-specific macroprudential policy, i.e. we allow the LTV ratios to be adjusted differently in the core and periphery. In this respect, we draw on the previous literature that demonstrated that such region-specific policy is much more effective in fighting asymmetric shocks than imposing the same LTV ratios in both regions.

A crucial question is how to evaluate the success of a policy. The boom-bust was a highly multidimensional experience - it affected output, credit, house prices, current accounts and a number of other important macrovariables. A standard measure to evaluate policies is social welfare, and we use this criterion while designing our counterfactual policies. However, we are also aware that our model does not feature several aspects of reality that may be of interest from the policymaker's perspective and that would ultimately (if accounted for) also affect welfare. Sovereign or banking sector defaults, as well as their macroeconomic consequences could serve as an example. For this reason, we also evaluate our policies looking at other indicators that concerned economists and policymakers during the boom-bust episode, like credit volatility or current account imbalances.

\subsection{Monetary and macroprudential policy transmission}

Before we present the counterfactual simulations, we provide a brief explanation of how macroprudential and monetary policies work in our model. Figure 6 presents the effects of a contractionary macroprudential policy shock in the peripheral economy, in which the LTV ratio is assumed to follow a simple AR(1) process with autoregression equal to 0.9. A tightening in the LTV ratio depresses credit, which in turn decreases demand for both consumption goods and housing ${ }^{12}$ Residential investment responds with a lag, therefore real house prices fall. The central bank reacts by decreasing the interest rate, but only marginally as the share of the periphery in the union is small.

The effects of a contractionary monetary policy shock are presented in Figure 7, for two cases. The solid lines show the responses under a constant LTV ratio while the dashed lines depict the case of active macroprudential policy. In the latter case, the LTV ratios in both regions react to credit and house prices, with the feedback coefficients optimized as described below. An increase in the interest rate results in a decline in GDP and inflation. Absent response from the macroprudential authority, this leads to a fall in credit and house prices, amplifying the contraction. However, if macroprudential policy is active, the LTV ratio and hence credit go up, which dampens the fall in GDP. The initial decrease in house prices is also reduced, but it takes them longer to return to the long-run level.

\footnotetext{
${ }^{12}$ In our linearized setting there is perfect symmetry between expansionary and contractionary macroprudential policy. In practice, it could be the case that adjustments in the LTV ratio work better in constraining credit growth, but are less efficient at stimulating it (see Brzoza-Brzezina et al., 2014). Since our main focus is on whether contractionary macroprudential policy prior to the crisis could have helped prevent the housing boom, we do not consider it a problem for our analysis.
} 


\subsection{Optimized monetary policy}

We first examine if single monetary policy, maximizing area-wide welfare, could have significantly changed the boom-bust scenario observed after the euro creation. To this end, we set $\gamma_{R}^{*}$ in the monetary policy rule 20 to the estimated value and search for optimal values of the feedback parameters $\gamma_{\pi}^{*}$ and $\gamma_{y}^{*}$. To be precise, we find the parameter values that maximize the second order approximation to the euro-wide welfare function defined as follows (see Rubio, 2011):

$$
U_{t} \equiv \omega\left[\omega_{P}\left(1-\beta_{P}\right) U_{P, t}+\omega_{I}\left(1-\beta_{I}\right) U_{I, t}\right]+(1-\omega)\left[\omega_{P}^{*}\left(1-\beta_{P}^{*}\right) U_{P, t}^{*}+\omega_{I}^{*}\left(1-\beta_{I}^{*}\right) U_{I, t}^{*}\right]
$$

Next, we generate a counterfactual path for the economy, starting from 4q1998 (i.e. just before the creation of the euro area), based on the welfare maximizing Taylor rule parameters.

Figure 8 presents the historical and counterfactual paths for a selection of variables. The policy has a clear stabilizing impact on GDP in the core and (somewhat less) in the periphery. The evolution of inflation is modified as well, although here the stabilizing effect is somewhat less visible. More importantly, however, the policy has only a negligible impact on credit, it also does not significantly affect the periphery's competitiveness as the path of its net exports barely changes. Table 7 presents welfare gains on the counterfactual path relative to the historical one, both extended into the future assuming no further shocks ${ }^{13}$ As can be seen, monetary policy was able to raise welfare for all types of agents, with highest gains pertaining to impatient households in the periphery. However, as already mentioned, these gains do not seem to go in line with a clear improvement with respect to the boom-bust developments.

Given the mixed findings using the welfare criterion, we also experiment with policies that explicitly target selected variables specific to the boom-bust cycle: house prices and credit. The findings (not reported as figures) are not very encouraging - single monetary policy is not able to modify the historical paths of the targeted variables in any meaningful way. All of these policies have also only a negligible impact on the periphery's trade balance.

\subsection{Optimized macroprudential policy}

Following the previous findings in the literature, we focus on region-specific macroprudential policy. More precisely, we optimize the feedback parameters $\gamma_{m l}, \gamma_{m p}, \gamma_{m l}^{*}, \gamma_{m p}^{*}$ of the macro-

\footnotetext{
${ }^{13}$ Welfare gains are calculated as follows. First, we extend the historical and counterfactual paths for an infinite horizon, assuming that no further shocks arrive after the end of our sample. Next, for both paths we calculate the discounted sums of period utilities for both types of agents of the two eurozone regions. The gains reported in Table 7 are expressed as steady state consumption equivalents. The area-wide gain is calculated as a weighted average using the shares of each type of agent in the eurozone population.
} 
prudential policy rules (22) in the core and periphery, not restricting them to be pairwise equal between the two regions. As before, we use the euro-wide welfare criterion given by equation (26). We have also constrained the set of outcomes such that the standard deviation of the macroprudential instrument (LTV ratio) is below 0.15 for each region, which guarantees that it remains within a reasonable range in our counterfactual scenarios.

Consistently with our finding that the periphery is structurally more prone to credit booms, we find that the optimal strength of the response of the LTV ratio in this region to housing market developments is bigger than in the core. Figure 9 shows the counterfactual paths of key macrovariables under such region-specific policies, assuming that their implementation begins in 4q1998. It is clear that agents in this model prefer to hold less credit at the onset of the crisis. A negative consequence of active macroprudential policy is that it generates short-lived and shallow recessions, which may be interpreted as a result of "popping" credit bubbles. Active policy also helps limit the loss in the periphery's competitiveness as it reduces the build-up of external imbalances ${ }^{14}$

The welfare impact of active macroprudential policy is reported in Table 7. For our historical sample, welfare effects are almost ubiquitously positive, with negligible welfare losses for patient households, and significant gains for impatient ones. The overall welfare gain is clearly positive and larger than that obtained with optimized monetary policy.

As before, we have also experimented with macroprudential policies directly aimed at stabilizing loans, house prices and the external balance. The policies attempting to stabilize loans and net exports generate similar paths to those obtained using our welfare criterion. This suggests that attempting to stabilize these indicators approximates welfare-based policies reasonably well. In contrast, targeting the euro-wide house price index has greatly destabilizing effects on other variables, especially in the core economy. This result may serve as a warning that attempting to stabilize certain variables, often treated as macroprudential policy targets, may have dire consequences for the overall economic performance.

\subsection{Optimized monetary-macroprudential policy mix}

In the previous two experiments, we have examined the effects of optimized monetary and macroprudential policies separately. We now look at the outcomes that could be achieved if these policies are implemented in a coordinated way. More specifically, we optimize the Taylor rule parameters and macroprudential policy rule coefficients in the core and periphery jointly to maximize euro-wide welfare.

\footnotetext{
${ }^{14}$ Gilbert and Pool (2016) argue that the problems in the periphery were associated with expansion of the non-tradable sector and hence go beyond the housing sector. It needs to be stressed, however, that the boom in non-housing industries of the periphery's non-tradable sector was by far less dramatic. More importantly, expansion of this part of the economy was not channeled through collateralized borrowing, and hence did not result in inefficiencies associated with pecuniary externalities such as those stressed e.g. by Jeanne and Korinek (2010).
} 
Figure 10 compares the historical and counterfactual paths for a selection of variables while Table 7 reports the resulting welfare gains. Overall, the outcomes are very similar to the case of optimized macroprudential policy alone, with slightly larger welfare gains for impatient agents, especially in the periphery. As regards the counterfactual paths, output in both regions appears to be smoother if monetary policy helps macroprudential authorities to optimally stabilize the euro area. However, most of the gains in welfare, as well as reduction in credit cycle and external imbalances, could have been achieved by macroprudential policy without the need to modify monetary policy. Interestingly, macroprudential policy helps monetary policy to avoid the zero lower bound problem - the gross interest rate remains strictly above unity throughout the simulation.

\section{Robustness}

\subsection{Monetary policy reacting to credit market developments}

Recently it has been argued that optimally monetary policy should react not only to inflation and output (gap), but also to developments in financial and credit markets. Juselius et al. (2016) perform a counterfactual analysis where monetary authority sets interest rates in reaction to the debt service gap, related to the ratio of credit to GDP in an economy. They find that this modification of the Taylor rule would improve outcomes during the last crisis. Following this direction, we allow the monetary policy rule in our model to react also to deviations of credit from trend. The result, reported in Table 8, suggests that within our framework reacting to developments in credit markets would not be welfare improving, as the reaction coefficient is found to be essentially zero. This does not mean however that creditaware monetary policy could not improve outcomes during the last crisis, but rather points out that given the estimated structure of shocks on average it is better for the monetary policy to react only to inflation and output. This result is consistent with the results of Svensson (2016) that reacting to credit growth entails substantial costs that exceed the benefits.

\subsection{Restricting sample to observations starting in 1999}

Our model assumes that prior to 1999 the nominal exchange rate between the core and periphery regions is set to 1 , as it is de facto after the adoption of euro. However, prior to the creation of the eurozone, nominal exchange rates did adjust, and our assumption could potentially bias the results of our estimation. Therefore, we reestimate the parameters of the model excluding all data before 1999. Subsequently, we find again the welfare-maximizing parameters of the optimal monetary, macroprudential, and coordinated monetary and macroprudential policies. The results are reported in Table 9. Parameters found under this variant 
are very similar to the parameters found in our baseline case. The optimal monetary policy now reacts slightly more strongly to deviations of GDP and optimal macroprudential policy now also reacts to the expansion of credit in the core. However, the parameters of coordinated policies are almost unchanged. Also, as seen in Table 10, the welfare effects of the policies are almost identical to the baseline variant, preserving both relative orderings as well as magnitudes. Figures 11, 13 and 15 show the effects of the counterfactual policies under this variant. The outcomes are virtually identical compared to the baseline variant.

\subsection{Including Italy in the periphery}

There is substantial disagreement in the literature on whether Italy shares more common characteristics with the core (e.g. Belke et al., 2017) or with the peripheral countries (e.g. Caporale et al., 2015). To make our results more robust, we have also reestimated a variant where Italy is removed from the core group and included in the periphery group. Despite this change, the majority of our results remained unchanged. As can be seen in Table

9. the optimal monetary policy now places more weight in stabilizing GDP, and the core macroprudential policy pays attention to the deviations of credit from the trend. However, once we consider the coordinated policies, the parameters of the eurozone-wide monetary policy, as well as peripheral macroprudential policy, are identical with those found in the baseline variant (despite the different composition of the peripheral region). Interestingly, excluding Italy from the core has changed the optimal parameters of the macroprudential rule in the core, as now it reacts very strongly to credit, ignoring changes in the housing prices. Therefore, in this variant the LTV ratio for core is systematically lowered until 2007, and is later systematically relaxed to alleviate the effects of the crisis, as evidenced by Figure 16. The welfare effects of the policies change slightly relative to the baseline due to different group composition. Of interest is that in this variant the aggregate welfare effect of monetary policy is stronger than the effect of macroprudential policy. Nevertheless, the aggregate welfare effect of the coordinated policies is almost identical to the one found in the baseline variant.

\section{Conclusions}

In this paper we ask whether policy - be it monetary or macroprudential - could have prevented the boom-bust cycle that plagued the euro area periphery. We draw on the literature that documented - albeit in stochastic simulations - that macroprudential policy can be relatively successful in stabilizing real and financial variables in a small region of the monetary union affected by asymmetric shocks. Our exercise is different in the sense that, instead of concentrating on a typical business cycle, we focus on the historical experience of the euro 
area. Our simulations are applied to the period 1998q4-2015q1, which covers the build-up and correction of imbalances in the euro area.

Our simulations are based on a two-country DSGE model estimated using euro area (core and periphery) data. We find that the imbalances were driven mainly by shocks related to the housing market in the periphery. We also show that this region is more vulnerable to boom-bust cycles originating in this sector because of its more rigid structure. Next we check whether single monetary policy could have prevented the boom-bust. We find that optimal monetary policy could have stabilized somewhat the business (GDP) cycle in the periphery, however the remaining variables typical for the boom-bust episode (house prices, loans, net exports) remain unaffected. In this respect, region-specific macroprudential policy does a much better job, smoothing not only output, but also the credit cycle and reducing the build-up of external imbalances in the periphery.

In this paper we have abstracted from sovereign default risk, even though it was at the heart of the recent Eurozone crisis. This choice was motivated by our willingness to focus on private sector developments, and in particular on the housing market and loss in international competitiveness. In this context, an important message of this paper is that even if the euro area manages to sort out its fiscal problems (i.e. by forming a fiscal union), there will still be need for leaning against housing booms with appropriately designed macroprudential policy as it has a potential to result in significant welfare gains.

An important question is whether this study has only a historical flavor. On the one hand, the answer is no. The recent experience of Ireland, where by 2015q3 house prices increased by $33 \%$ from its post-crisis low achieved in $2013 \mathrm{q} 1$ (source: BIS) suggests that the problem of asymmetric housing market developments may reappear. On the other hand, it is possible that both banks and households have learned a lesson from the previous episode and a fully-fledged boom-bust cycle will not reemerge in the near future ${ }^{15}$ Our view is that some lesson has been drawn, but not for very long. Unfortunately, our model cannot answer this intriguing question, which surely deserves further research.

Finally, let us note that while this paper focuses on optimal adjustments in monetary and macroprudential instruments, we see its policy implications as much broader. In particular, by being suggestive about which asymmetric developments in the euro area are damaging from the social welfare perspective and hence should be combated, the outcomes of our counterfactual simulations may provide support to the Macroeconomic Imbalances Procedure.

\footnotetext{
${ }^{15}$ For instance, Gros $(2016)$ suggests that more cautious capital markets and a more elastic labor market should be able to solve the problem in the future.
} 


\section{References}

Álvarez, Luis J., Emmanuel Dhyne, Marco Hoeberichts, Claudia Kwapil, Hervé Le Bihan, Patrick Lünnemann, Fernando Martins, Roberto Sabbatini, Harald Stahl, Philip Vermeulen, and Jouko Vilmunen (2006) 'Sticky Prices in the Euro Area: A Summary of New Micro-Evidence.' Journal of the European Economic Association 4(2-3), 575-584

An, Sungbae, and Frank Schorfheide (2007) 'Bayesian analysis of DSGE models.' Econometric Reviews 26(2-4), 113-172

Andreasen, Martin (2010) 'How to Maximize the Likelihood Function for a DSGE Model.' Computational Economics 35(2), 127-154

Bayoumi, Tamim, and Barry Eichengreen (1992) 'Shocking Aspects of European Monetary Unification.' NBER Working Papers 3949, National Bureau of Economic Research, Inc, January

Belke, Ansgar, and Jens Klose (2017) 'Equilibrium real interest rates and secular stagnation: An empirical analysis for euro area member countries.' Journal of Common Market Studies p. forthcoming

Belke, Ansgar, Clemens Domnick, and Daniel Gros (2017) 'Business Cycle Synchronization in the EMU: Core vs. Periphery.' Open Economies Review p. forthcoming

Blanchard, Olivier (2007) 'Adjustment within the euro. The difficult case of Portugal.' Portuguese Economic Journal 6(1), 1-21

Blanchard, Olivier, and Francesco Giavazzi (2002) 'Current account deficits in the euro area: The end of the Feldstein Horioka puzzle?' Brookings Papers on Economic Activity $33(2002-2), 147-210$

Brooks, Stephen, and Andrew Gelman (1998) 'Some issues in monitoring convergence of iterative simulations.' In 'Proceedings of the Section on Statistical Computing' American Statistical Association.

Brzoza-Brzezina, Michał (2005) 'Lending booms in the new EU Member States: will euro adoption matter?' Working Paper Series 0543, European Central Bank

Brzoza-Brzezina, Michał, Marcin Kolasa, and Krzysztof Makarski (2015) 'Macroprudential policy and imbalances in the euro area.' Journal of International Money and Finance 51(C), 137-154 
Brzoza-Brzezina, Michał, Marcin Kolasa, and Paolo Gelain (2014) 'Monetary and macroprudential policy with multiperiod loans.' NBP Working Papers 192, Narodowy Bank Polski

Bussiere, Matthieu, Giovanni Callegari, Fabio Ghironi, Giulia Sestieri, and Norihiko Yamano (2013) 'Estimating trade elasticities: Demand composition and the trade collapse of 20082009.' American Economic Journal: Macroeconomics 5(3), 118-51

Campos, Nauro F., and Corrado Macchiarelli (2016) 'Core and Periphery in the European Monetary Union: Bayoumi and Eichengreen 25 years later.' Economics Letters $147(\mathrm{C}), 127-130$

Caporale, Guglielmo Maria, Roberta De Santis, and Alessandro Girardi (2015) 'Trade intensity and output synchronisation: On the endogeneity properties of EMU.' Journal of Financial Stability 16, 154-163

Chang, Yongsung, Sun-Bin Kim, and Frank Schorfheide (2013) 'Labor-Market Heterogeneity, Aggregation, And Policy (In)Variance Of Dsge Model Parameters.' Journal of the European Economic Association 11, 193-220

Chen, Ruo, Gian Maria Milesi-Ferretti, and Thierry Tressel (2013) 'External imbalances in the eurozone.' Economic Policy 28(73), 101-142

Christiano, Lawrence J., Martin Eichenbaum, and Charles L. Evans (2005) 'Nominal rigidities and the dynamic effects of a shock to monetary policy.' Journal of Political Economy $113(1), 1-45$

Claessens, Stijn (2014) 'An Overview of Macroprudential Policy Tools.' IMF Working Papers 14/214, International Monetary Fund

Coenen, Günter, Peter McAdam, and Roland Straub (2008) 'Tax reform and labour-market performance in the euro area: A simulation-based analysis using the New Area-Wide Model.' Journal of Economic Dynamics and Control 32(8), 2543-2583

Darracq-Pariés, Matthieu, Christoffer Kok Sorensen, and Diego Rodriguez-Palenzuela (2011) 'Macroeconomic propagation under different regulatory regimes: Evidence from an estimated DSGE model for the euro area.' International Journal of Central Banking 7(4), 49113

De Grauwe, Paul, and Yuemei Ji (2016) 'Flexibility Versus Stability: A Difficult Tradeoff in the Eurozone.' Credit and Capital Markets 49(3), 375-413 
Fagan, Gabriel, and Vitor Gaspar (2007) 'Adjusting to the euro.' Working Paper Series 716, European Central Bank

Geanakoplos, John (2010) 'The Leverage Cycle.' In 'NBER Macroeconomics Annual 2009, Volume 24' NBER Chapters (National Bureau of Economic Research, Inc) pp. 1-65

Gilbert, Niels, and Sebastiaan Pool (2016) 'Sectoral allocation and macroeconomic imbalances in EMU.' DNB Working Papers 536, Netherlands Central Bank, Research Department

Gros, Daniel (2016) 'Adjustment within the Euro Area: Is it all about competitiveness?' CEPS Special Report 127, Centre for European Policy Studies

Hirose, Yasuo, and Atsushi Inoue (2015) 'The zero lower bound and parameter bias in an estimated dsge model.' Journal of Applied Econometrics pp. n/a-n/a

Honohan, Patrick, and Anthony J. Leddin (2006) 'Ireland in EMU - more shocks, less insulation?' The Economic and Social Review 37(2), 263-294

Iacoviello, Matteo (2005) 'House prices, borrowing constraints, and monetary policy in the business cycle.' American Economic Review 95(3), 739-764

in’t Veld, Jan, Andrea Pagano, Rafal Raciborski, Marco Ratto, and Werner Roeger (2012) 'Imbalances and rebalancing scenarios in an estimated structural model for Spain.' European Economy - Economic Papers 458, Directorate General Economic and Monetary Affairs (DG ECFIN), European Commission

Jeanne, Olivier, and Anton Korinek (2010) 'Managing credit booms and busts: A pigouvian taxation approach.' NBER Working Papers 16377, National Bureau of Economic Research, Inc

Juselius, Mikael, Claudio Borio, Piti Disyatat, and Mathias Drehmann (2016) 'Monetary policy, the financial cycle and ultra-low interest rates.' Technical Report 569, Bank for International Settlements

Justiniano, Alejandro, Giorgio E. Primiceri, and Andrea Tambalotti (2015) 'Credit Supply and the Housing Boom.' NBER Working Papers 20874, National Bureau of Economic Research, Inc

Lambertini, Luisa, Caterina Mendicino, and Maria Teresa Punzi (2013) 'Leaning against boom-bust cycles in credit and housing prices.' Journal of Economic Dynamics and Control $37(8), 1500-1522$ 
Landvoigt, Tim, Monika Piazzesi, and Martin Schneider (2015) 'The housing market(s) of San Diego.' American Economic Review 105(4), 1371-1407

Lucas, Robert E. (1976) 'Econometric policy evaluation: A critique.' Carnegie-Rochester Conference Series on Public Policy 1, pp. 19-46

Martin, Philippe, and Thomas Philippon (2017) 'Inspecting the mechanism: Leverage and the Great Recession in the eurozone.' American Economic Review, forthcoming

Quint, Dominic, and Pau Rabanal (2014) 'Monetary and macroprudential policy in an estimated DSGE model of the euro area.' International Journal of Central Banking 10(2), 169236

Rubio, Margarita (2011) 'Fixed- and variable-rate mortgages, business cycles, and monetary policy.' Journal of Money, Credit and Banking 43(4), 657-688

_ (2014) 'Macroprudential Policy Implementation in a Heterogeneous Monetary Union.' Discussion Papers 2014/03, University of Nottingham, Centre for Finance, Credit and Macroeconomics (CFCM)

Smets, Frank, and Rafael Wouters (2007) 'Shocks and frictions in us business cycles: A bayesian DSGE approach.' American Economic Review 97(3), 586-606

Svensson, Lars E. O. (2016) 'Cost-Benefit Analysis of Leaning Against the Wind; Are Costs Larger Also with Less Effective Macroprudential Policy?' Technical Report 16/3, International Monetary Fund 


\section{Tables and figures}

Table 1: Calibration - parameters

\begin{tabular}{ccl}
\hline Parameter & Value & Description \\
\hline$\beta_{P}, \beta_{P}^{*}$ & 0.998 & Discount factor, patient HHs \\
$\beta_{I}, \beta_{I}^{*}$ & 0.983 & Discount factor, impatient HHs \\
$\delta_{\chi}, \delta_{\chi}^{*}$ & 0.01 & Housing stock depreciation rate \\
$\omega_{I}$ & 0.675 & Share of impatient HHs in periphery \\
$\omega_{I}^{*}$ & 0.5 & Share of impatient HHs in core \\
$A_{\chi}, A_{\chi}^{*}$ & 1.67 & Weight on housing in utility function (see footnote 5$)$ \\
$A_{n}, A_{n}^{*}$ & 35.1 & Weight on labor in utility function (see footnote 5 ) \\
$\sigma_{c}, \sigma_{c}^{*}$ & 2 & Inverse of intertemporal elasticity of substitution in consumption \\
$\sigma_{\chi}, \sigma_{\chi}^{*}$ & 2 & Inverse of intertemporal elasticity of substitution in housing \\
$\sigma_{n}, \sigma_{n}^{*}$ & 2 & Inverse of Frisch elasticity of labor supply \\
$\mu_{w}, \mu_{w}^{*}$ & 1.2 & Steady state wage markup \\
$\phi_{n}, \phi_{n}^{*}$ & 6 & Elasticity of substitution btw. labor of patient and impatient HHs \\
$\tau_{I}, \tau_{I}^{*}$ & 0.25 & Real transfers from patient to impatient HHs \\
$\mu, \mu^{*}$ & 1.2 & Steady state product markup \\
$\alpha, \alpha^{*}$ & 0.3 & Output elasticity with respect to physical capital \\
$k, k^{*}$ & 6.7 & physical capital stock per capita \\
$\mu_{L}, \mu_{L}^{*}$ & 1.0047 & Loan markup \\
$m_{\chi}, m_{\chi}^{*}$ & 0.75 & Steady state LTV ratio \\
$\pi, \pi^{*}$ & 1.005 & Steady state inflation \\
$\xi$ & 0.001 & Elasticity of risk premium wrt. foreign debt \\
$\omega$ & 0.168 & Share of periphery in monetary union \\
$\eta_{H}$ & 0.70 & Share of domestic goods in consumption basket (periphery) \\
$\phi_{f}, \phi_{f}^{*}$ & 0.06 & Share of imported goods in consumption basket (core) \\
$\eta_{H}^{*}(1-5$ & Elasticity of substitution btw. home and foreign goods \\
\hline
\end{tabular}

Table 2: Steady state ratios

\begin{tabular}{lc}
\hline Steady state ratio & Value \\
\hline Import to GDP ratio (periphery) & 0.27 \\
Import to GDP ratio (core) & 0.06 \\
Government spending to GDP ratio & 0.25 \\
Residential investment to GDP ratio & 0.07 \\
Capital-GDP ratio (annual) & 2.0 \\
Hours worked & 0.33 \\
Housing wealth to GDP ratio (annual) & 1.78 \\
Debt to GDP ratio (annual, periphery) & 0.70 \\
Debt to GDP ratio (annual, core) & 0.52 \\
Spread (annualized) & 0.019 \\
\hline
\end{tabular}


Table 3: Prior and posterior distribution: structural parameters

\begin{tabular}{l|ccc|ccc}
\hline Parameter & \multicolumn{3}{|c|}{ Prior distribution } & \multicolumn{3}{c}{ Posterior distribution } \\
& type & Mean & St. Dev. & Mode & Mean & St. Dev. \\
\hline$\xi_{c}$ & beta & 0.50 & 0.20 & 0.82 & 0.82 & 0.03 \\
$\xi_{c}^{*}$ & beta & 0.50 & 0.20 & 0.73 & 0.77 & 0.05 \\
$\xi_{\chi}$ & beta & 0.50 & 0.20 & 0.46 & 0.45 & 0.25 \\
$\xi_{\chi}^{*}$ & beta & 0.50 & 0.20 & 0.59 & 0.52 & 0.32 \\
$\theta_{w}$ & beta & 0.75 & 0.05 & 0.84 & 0.83 & 0.03 \\
$\theta_{w}^{*}$ & beta & 0.75 & 0.05 & 0.78 & 0.78 & 0.04 \\
$\zeta_{w}$ & beta & 0.50 & 0.20 & 0.79 & 0.67 & 0.16 \\
$\zeta_{w}^{*}$ & beta & 0.50 & 0.20 & 0.80 & 0.72 & 0.15 \\
$\kappa_{\chi}$ & norm & 30.0 & 10.0 & 23.0 & 22.8 & 2.90 \\
$\kappa_{\chi}^{*}$ & norm & 30.0 & 10.0 & 9.12 & 9.42 & 1.26 \\
$\theta_{H}$ & beta & 0.75 & 0.05 & 0.91 & 0.91 & 0.02 \\
$\theta_{F}^{*}$ & beta & 0.75 & 0.05 & 0.91 & 0.91 & 0.01 \\
$\theta_{F}$ & beta & 0.75 & 0.05 & 0.83 & 0.84 & 0.03 \\
$\theta_{H}^{*}$ & beta & 0.75 & 0.05 & 0.80 & 0.78 & 0.04 \\
$\zeta_{H}$ & beta & 0.50 & 0.20 & 0.14 & 0.23 & 0.10 \\
$\zeta_{F}^{*}$ & beta & 0.50 & 0.20 & 0.21 & 0.34 & 0.13 \\
$\zeta_{F}$ & beta & 0.50 & 0.20 & 0.40 & 0.48 & 0.25 \\
$\zeta_{H}^{*}$ & beta & 0.50 & 0.20 & 0.44 & 0.47 & 0.27 \\
$\xi$ & beta & 0.005 & 0.002 & 0.002 & 0.002 & 0.00 \\
$\gamma_{R}^{*}$ & beta & 0.90 & 0.05 & 0.89 & 0.88 & 0.01 \\
$\gamma_{\pi}^{*}$ & norm & 1.70 & 0.10 & 1.51 & 1.59 & 0.12 \\
$\gamma_{y}^{*}$ & beta & 0.125 & 0.005 & 0.03 & 0.06 & 0.01 \\
\hline
\end{tabular}


Table 4: Prior and posterior distribution: shocks

\begin{tabular}{|c|c|c|c|c|c|c|}
\hline \multirow[t]{2}{*}{ Parameter } & \multicolumn{3}{|c|}{ Prior distribution } & \multicolumn{3}{|c|}{ Posterior distribution } \\
\hline & type & Mean & St. Dev. & Mode & Mean & St. Dev. \\
\hline$\rho_{u}$ & beta & 0.70 & 0.10 & 0.74 & 0.71 & 0.07 \\
\hline$\rho_{u}^{*}$ & beta & 0.70 & 0.10 & 0.95 & 0.84 & 0.06 \\
\hline$\rho_{\chi}$ & beta & 0.70 & 0.10 & 0.98 & 0.98 & 0.01 \\
\hline$\rho_{\chi}^{*}$ & beta & 0.70 & 0.10 & 0.97 & 0.96 & 0.01 \\
\hline$\rho_{i \chi}$ & beta & 0.70 & 0.10 & 0.77 & 0.76 & 0.03 \\
\hline$\rho_{i \chi}^{*}$ & beta & 0.70 & 0.10 & 0.57 & 0.54 & 0.05 \\
\hline$\rho_{z}$ & beta & 0.70 & 0.10 & 0.36 & 0.37 & 0.06 \\
\hline$\rho_{z}^{*}$ & beta & 0.70 & 0.10 & 0.21 & 0.21 & 0.05 \\
\hline$\rho_{\mu_{L}}$ & beta & 0.70 & 0.10 & 0.92 & 0.91 & 0.03 \\
\hline$\rho_{\mu_{L}}^{*}$ & beta & 0.70 & 0.10 & 0.88 & 0.87 & 0.03 \\
\hline$\rho_{\mu}$ & beta & 0.70 & 0.10 & 0.84 & 0.80 & 0.05 \\
\hline$\rho_{\mu}^{*}$ & beta & 0.70 & 0.10 & 0.70 & 0.64 & 0.09 \\
\hline$\rho_{g}$ & beta & 0.70 & 0.10 & 0.89 & 0.88 & 0.04 \\
\hline$\rho_{g}^{*}$ & beta & 0.70 & 0.10 & 0.90 & 0.89 & 0.03 \\
\hline$\rho_{\xi}$ & beta & 0.70 & 0.10 & 0.97 & 0.97 & 0.01 \\
\hline$\rho_{n x}$ & beta & 0.70 & 0.10 & 0.93 & 0.93 & 0.02 \\
\hline$\sigma_{u}$ & invg & 0.01 & $\operatorname{Inf}$ & 0.13 & 0.14 & 0.02 \\
\hline$\sigma_{u}^{*}$ & invg & 0.01 & $\operatorname{Inf}$ & 0.05 & 0.06 & 0.01 \\
\hline$\sigma_{\chi}$ & invg & 0.01 & Inf & 0.17 & 0.19 & 0.02 \\
\hline$\sigma_{\chi}^{*}$ & invg & 0.01 & $\operatorname{Inf}$ & 0.08 & 0.10 & 0.02 \\
\hline$\sigma_{i \chi}$ & invg & 0.01 & Inf & 0.23 & 0.24 & 0.04 \\
\hline$\sigma_{i \chi}^{*}$ & invg & 0.01 & $\operatorname{Inf}$ & 0.12 & 0.13 & 0.02 \\
\hline$\sigma_{z}$ & invg & 0.01 & Inf & 0.05 & 0.05 & 0.00 \\
\hline$\sigma_{z}^{*}$ & invg & 0.01 & $\operatorname{Inf}$ & 0.03 & 0.03 & 0.00 \\
\hline$\sigma_{R}^{*}$ & invg & 0.001 & Inf & 0.001 & 0.001 & 0.00 \\
\hline$\sigma_{\mu_{L}}$ & invg & 0.001 & $\operatorname{Inf}$ & 0.001 & 0.001 & 0.00 \\
\hline$\sigma_{\mu_{L}}^{*}$ & invg & 0.001 & $\operatorname{Inf}$ & 0.001 & 0.001 & 0.00 \\
\hline$\sigma_{\mu}$ & invg & 0.01 & $\operatorname{Inf}$ & 0.06 & 0.07 & 0.02 \\
\hline$\sigma_{\mu}^{*}$ & invg & 0.01 & Inf & 0.07 & 0.09 & 0.02 \\
\hline$\sigma_{g}$ & invg & 0.01 & Inf & 0.02 & 0.02 & 0.00 \\
\hline$\sigma_{g}^{*}$ & invg & 0.01 & $\operatorname{Inf}$ & 0.01 & 0.01 & 0.00 \\
\hline$\sigma_{\xi}$ & invg & 0.001 & Inf & 0.001 & 0.001 & 0.00 \\
\hline$\sigma_{n x}$ & invg & 0.01 & Inf & 0.005 & 0.005 & 0.00 \\
\hline
\end{tabular}


Table 5: Variance decomposition - core

\begin{tabular}{lcccccc}
\hline Variable \Shock & $\begin{array}{c}\text { Housing } \\
\text { demand }\end{array}$ & $\begin{array}{c}\text { Housing } \\
\text { supply }\end{array}$ & $\begin{array}{c}\text { Other } \\
\text { demand }\end{array}$ & $\begin{array}{c}\text { Other } \\
\text { supply }\end{array}$ & Monetary Foreign \\
\hline GDP-I & 25.8 & 7.8 & 27.2 & 21.8 & 12.3 & 5.1 \\
Consumption & 27.4 & 13.3 & 29.9 & 18.9 & 9.6 & 0.8 \\
Residential investment & 31.3 & 57.3 & 5.6 & 4.3 & 0.9 & 0.6 \\
Mortgage loans & 20.9 & 27.5 & 7.9 & 38.7 & 2.0 & 3.0 \\
Real house prices & 43.4 & 17.8 & 6.5 & 20.6 & 10.9 & 0.8 \\
Mortgage interest rate & 1.6 & 0.7 & 31.3 & 33.7 & 24.3 & 8.5 \\
Inflation & 0.4 & 0.2 & 4.9 & 89.8 & 1.9 & 2.9 \\
\hline
\end{tabular}

Note: The shock groupings are as follows. Housing preference, housing investment and monetary policy shocks that hit the core have their own groups called 'Housing demand', 'Housing supply' and 'Monetary', respectively. 'Other demand' group collects the core's time preference, loan markup and government spending shocks. Technology and product markup shocks of the core populate 'Other supply' group. 'Foreign' group aggregates all shocks originating in the periphery, including the risk premium and rest of the world net exports shocks.

Table 6: Variance decomposition - periphery

\begin{tabular}{lcccccc}
\hline Variable \Shock & $\begin{array}{c}\text { Housing } \\
\text { demand }\end{array}$ & $\begin{array}{c}\text { Housing } \\
\text { supply }\end{array}$ & $\begin{array}{c}\text { Other } \\
\text { demand }\end{array}$ & $\begin{array}{c}\text { Other } \\
\text { supply }\end{array}$ & Monetary Foreign \\
\hline GDP-I & 41.2 & 17.3 & 7.2 & 13.3 & 4.4 & 16.7 \\
Consumption & 47.6 & 22.5 & 9.1 & 12.8 & 2.2 & 5.9 \\
Residential investment & 31.2 & 65.1 & 0.6 & 2.2 & 0.1 & 0.9 \\
Mortgage loans & 43.9 & 17.4 & 2.3 & 30.3 & 0.3 & 5.9 \\
Real house prices & 55.1 & 22.7 & 4.2 & 10.8 & 2.0 & 5.2 \\
Mortgage interest rate & 1.1 & 0.6 & 18.8 & 5.3 & 20.5 & 53.8 \\
Inflation & 0.3 & 0.3 & 0.3 & 93.9 & 0.9 & 4.4 \\
\hline
\end{tabular}

Note: The shock groupings are as follows. Housing preference, housing investment and monetary policy shocks that hit the periphery have their own groups called 'Housing demand', 'Housing supply' and 'Monetary', respectively. 'Other demand' group collects the periphery's time preference, loan markup and government spending shocks. Technology and product markup shocks of the periphery populate 'Other supply' group. 'Foreign' group aggregates all shocks originating outside of the periphery, as well as the risk premium and rest of the world net exports shocks.

Table 7: Welfare effects of optimized policies

\begin{tabular}{lccc}
\hline Agent \Policy & $\begin{array}{c}\text { Monetary } \\
\text { policy }\end{array}$ & $\begin{array}{c}\text { Macroprudential } \\
\text { policy }\end{array}$ & $\begin{array}{c}\text { Both } \\
\text { policies }\end{array}$ \\
\hline Patient (periphery) & 0.00 & -0.00 & -0.00 \\
Impatient (periphery) & 0.40 & 1.12 & 1.20 \\
Patient (core) & 0.00 & -0.00 & -0.00 \\
Impatient (core) & 0.26 & 0.24 & 0.26 \\
All agents & 0.16 & 0.23 & 0.24
\end{tabular}

Note: The table presents the welfare gains on the counterfactual path over the historical path. Gains are expressed in percent of steady state consumption. 
Table 8: Robustness: Optimal monetary policy rule parameters

\begin{tabular}{lccc}
\hline Variant \Parameters & $\gamma_{\pi}^{*}$ & $\gamma_{y}^{*}$ & $\gamma_{l}^{*}$ \\
\hline Baseline & 1 & 0.36 & - \\
Reacting to eurozone credit & 1 & 0.33 & 0.00 \\
\hline
\end{tabular}

Table 9: Robustness: Optimal monetary and macroprudential policy parameters

\begin{tabular}{llcccccc}
\hline Variant & Scenario \Parameters & $\gamma_{\pi}^{*}$ & $\gamma_{y}^{*}$ & $\gamma_{m l}$ & $\gamma_{m p}$ & $\gamma_{m l}^{*}$ & $\gamma_{m p}^{*}$ \\
\hline \multirow{2}{*}{ Baseline } & Monetary policy & 1 & 0.36 & - & - & - & - \\
& Macroprudential policy & - & - & -0.06 & -0.90 & -0.06 & -0.80 \\
& Coordinated policies & 1 & 0.26 & -0.05 & -0.85 & 0.00 & -0.70 \\
\hline Sample & Monetary policy & 1 & 0.65 & - & - & - & - \\
from & Macroprudential policy & - & - & 0 & -0.92 & -0.31 & -0.97 \\
1999 & Coordinated policies & 1 & 0.40 & -0.00 & -0.90 & -0.04 & -0.84 \\
\hline Italy & Optimal monetary policy & 1 & 0.65 & - & - & - & - \\
in & Macroprudential policy & - & - & 0 & -0.93 & -0.35 & -0.99 \\
periphery & Coordinated policies & 1 & 0.23 & -0.00 & -0.87 & -1.48 & -0.00 \\
\hline
\end{tabular}

Table 10: Robustness: Welfare effects of optimized policies

\begin{tabular}{llccc}
\hline Variant & Agent \Policy & $\begin{array}{c}\text { Monetary } \\
\text { policy }\end{array}$ & $\begin{array}{c}\text { Macroprudential } \\
\text { policy }\end{array}$ & $\begin{array}{c}\text { Coordinated } \\
\text { policies }\end{array}$ \\
\hline \multirow{5}{*}{ Baseline } & Patient (periphery) & 0.00 & -0.00 & -0.00 \\
& Impatient (periphery) & 0.40 & 1.12 & 1.20 \\
& Patient (core) & 0.00 & -0.00 & -0.00 \\
& Impatient (core) & 0.26 & 0.24 & 0.26 \\
& All agents & 0.16 & 0.23 & 0.24 \\
\hline \multirow{2}{*}{ Sample } & Patient (periphery) & 0.00 & -0.00 & -0.01 \\
from & Impatient (periphery) & 0.38 & 1.24 & 1.28 \\
& Patient (core) & 0.00 & -0.00 & -0.00 \\
& Impatient (core) & 0.16 & 0.24 & 0.16 \\
Italy & All agents & 0.11 & 0.24 & 0.21 \\
in & Patient (periphery) & 0.00 & -0.00 & -0.00 \\
periphery & Impatient (periphery) & 0.72 & 0.50 & 0.70 \\
& Patient (core) & 0.00 & -0.00 & -0.00 \\
\hline
\end{tabular}


Figure 1: Stylized facts on imbalances in the euro area

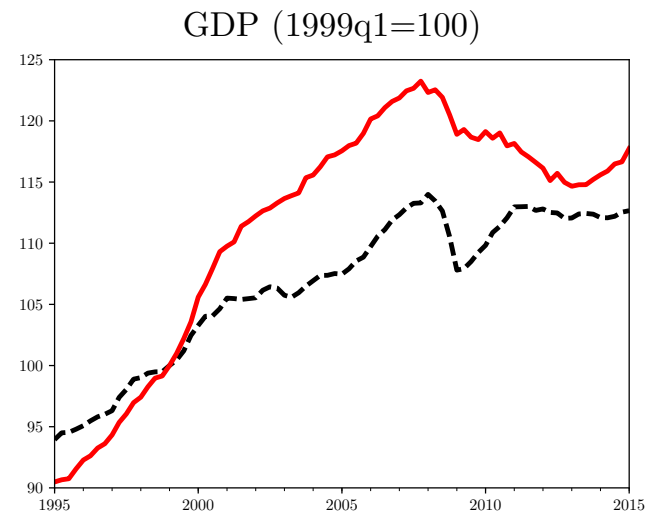

Price level $(1999 \mathrm{q} 1=100)$

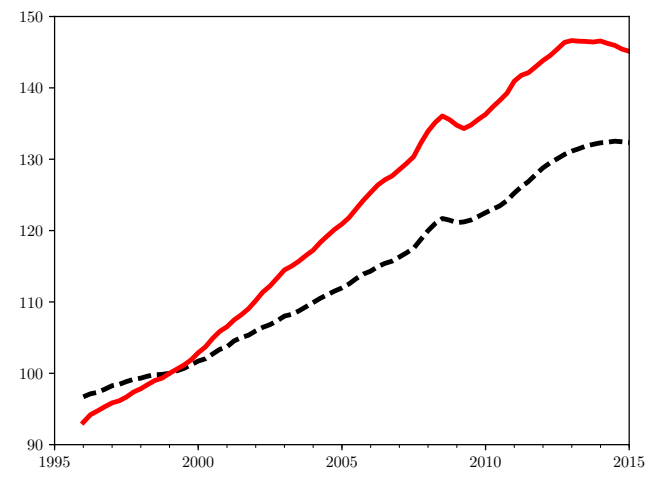

Housing loans $(1999 \mathrm{q} 1=100)$

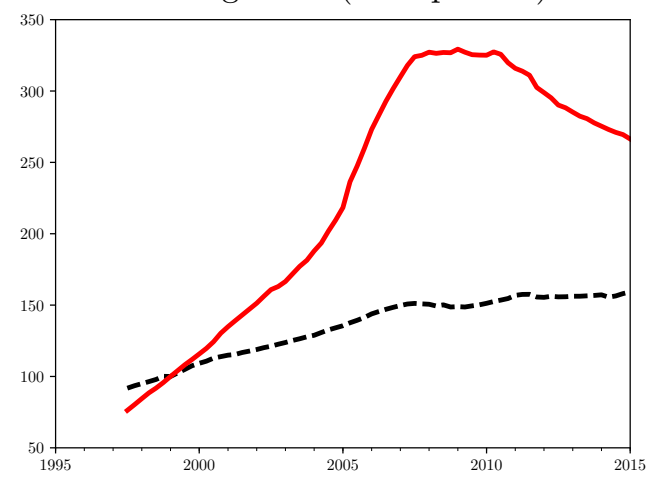

Residential investment $(1999 \mathrm{q} 1=100)$

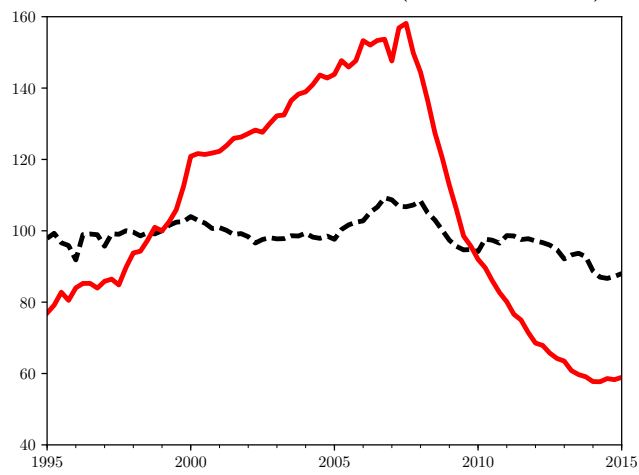

Net exports as share of GDP

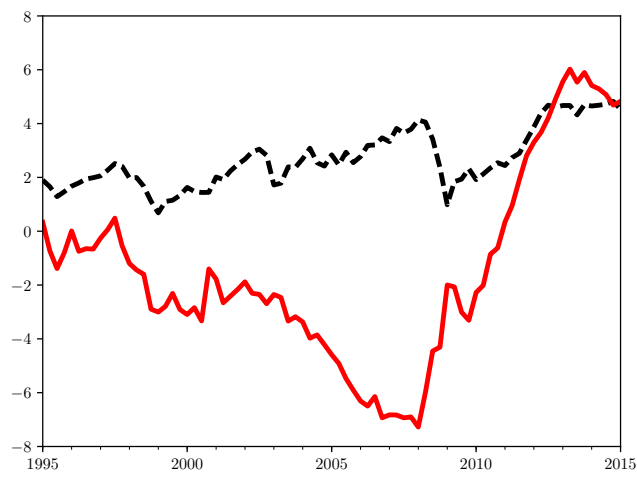

Real house prices $(1999 \mathrm{q} 1=100)$

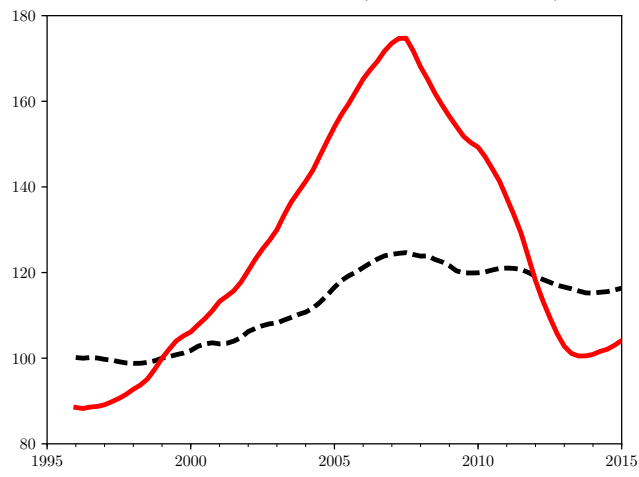

Note: Black dashed lines - core euro area members (Austria, Belgium, Finland, France, Germany, Italy, Luxembourg, Netherlands), red solid lines - peripheral euro area members (Greece, Ireland, Portugal and Spain). For each country, GDP is real gross domestic product (source: Eurostat), residential investment is real investment in dwellings (source: Eurostat), price level is the Harmonized Index of Consumer Prices (HICP, source: Eurostat), net exports as share of GDP is real net exports divided by real GDP (source: Eurostat), house prices are residential property prices of new and existing houses and flats (source: ECB SDW and BIS), while housing loans are defined as outstanding amounts of lending for house purchase (source: ECB SDW). The last two series are deflated by HICP (source: Eurostat). The aggregates for both regions are calculated as sums (GDP, residential investment, net exports and loans) or GDP-weighted averages (price level, house prices). Aggregated GDP, residential investment and loans are divided by total population (source: Eurostat) in the respective country groups. 
Figure 2: Prior and posterior densities for estimated structural parameters (part 1)
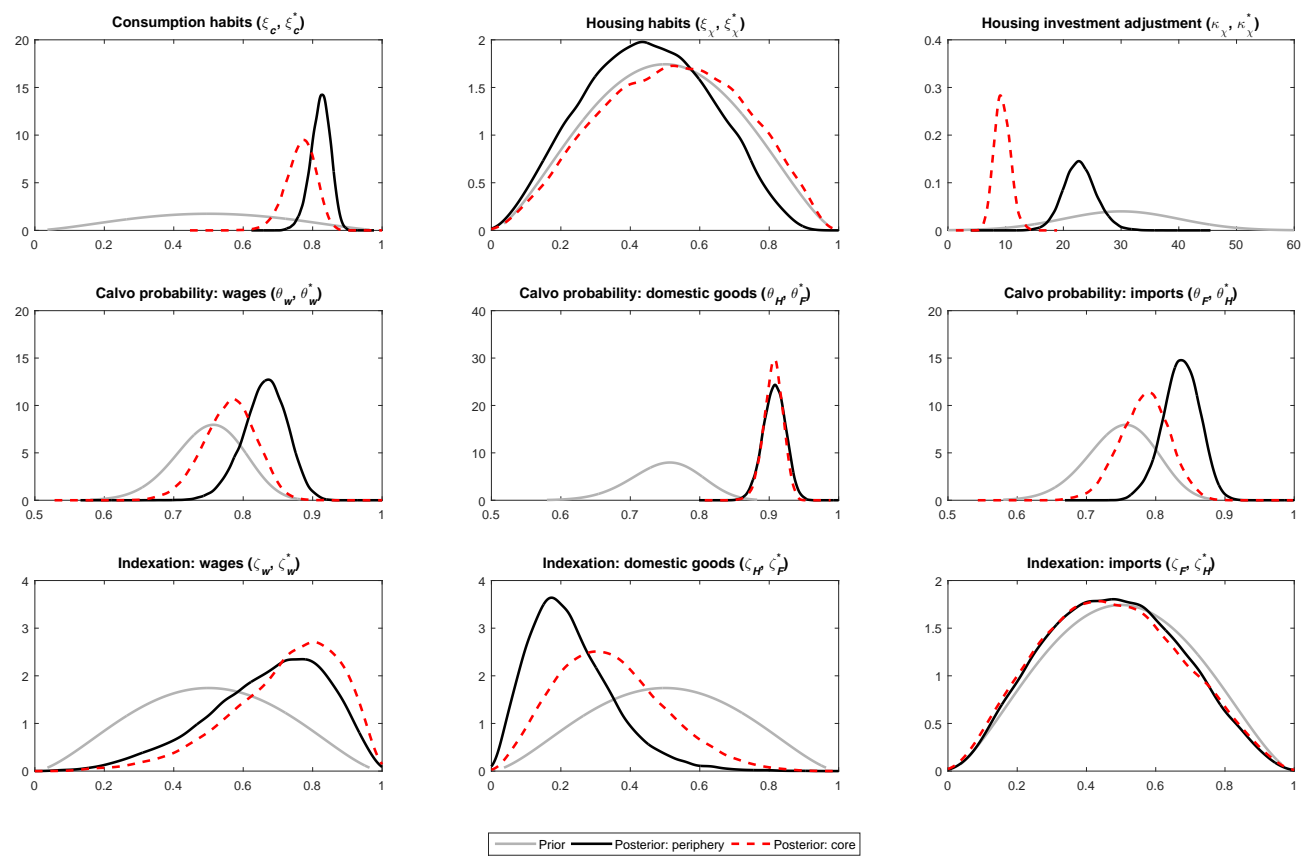

Figure 3: Prior and posterior densities for estimated structural parameters (part 2)
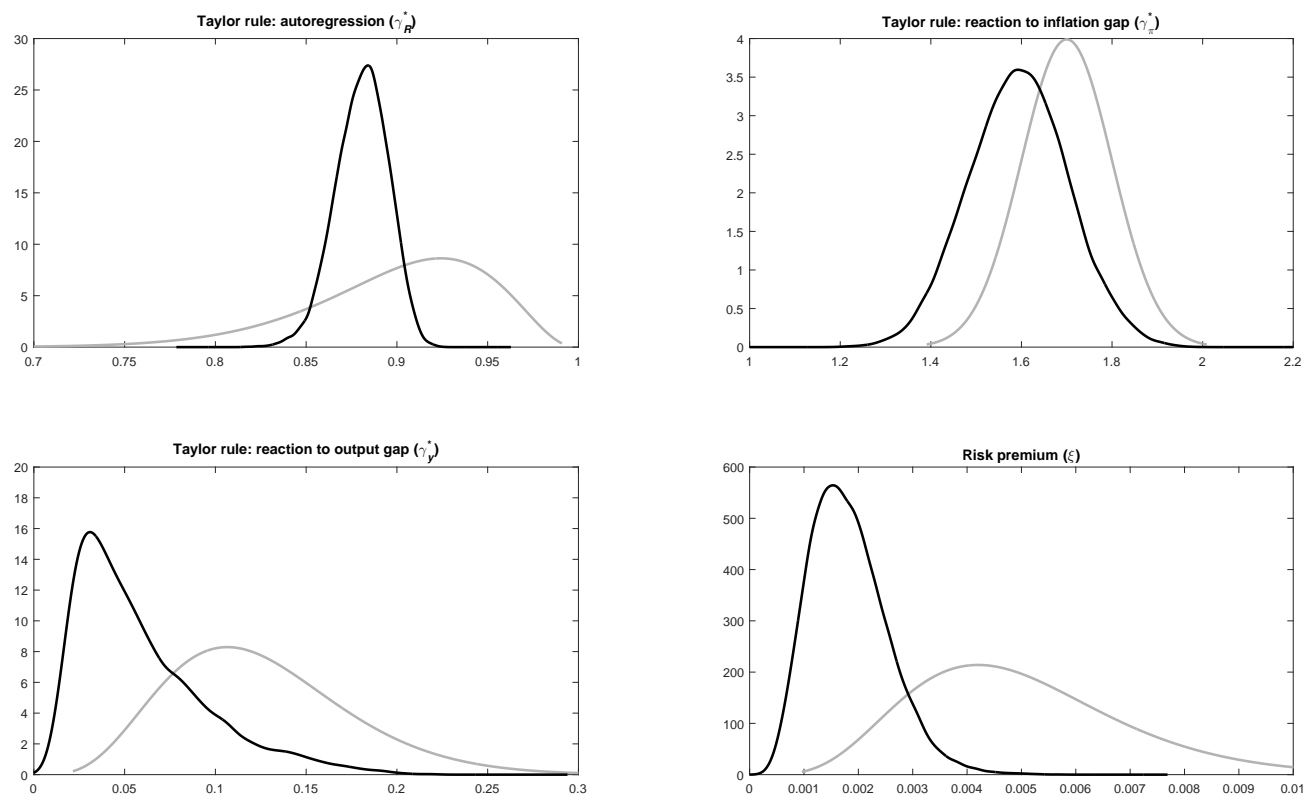

- Prior — Posterior 
Figure 4: Historical shock decomposition in the periphery
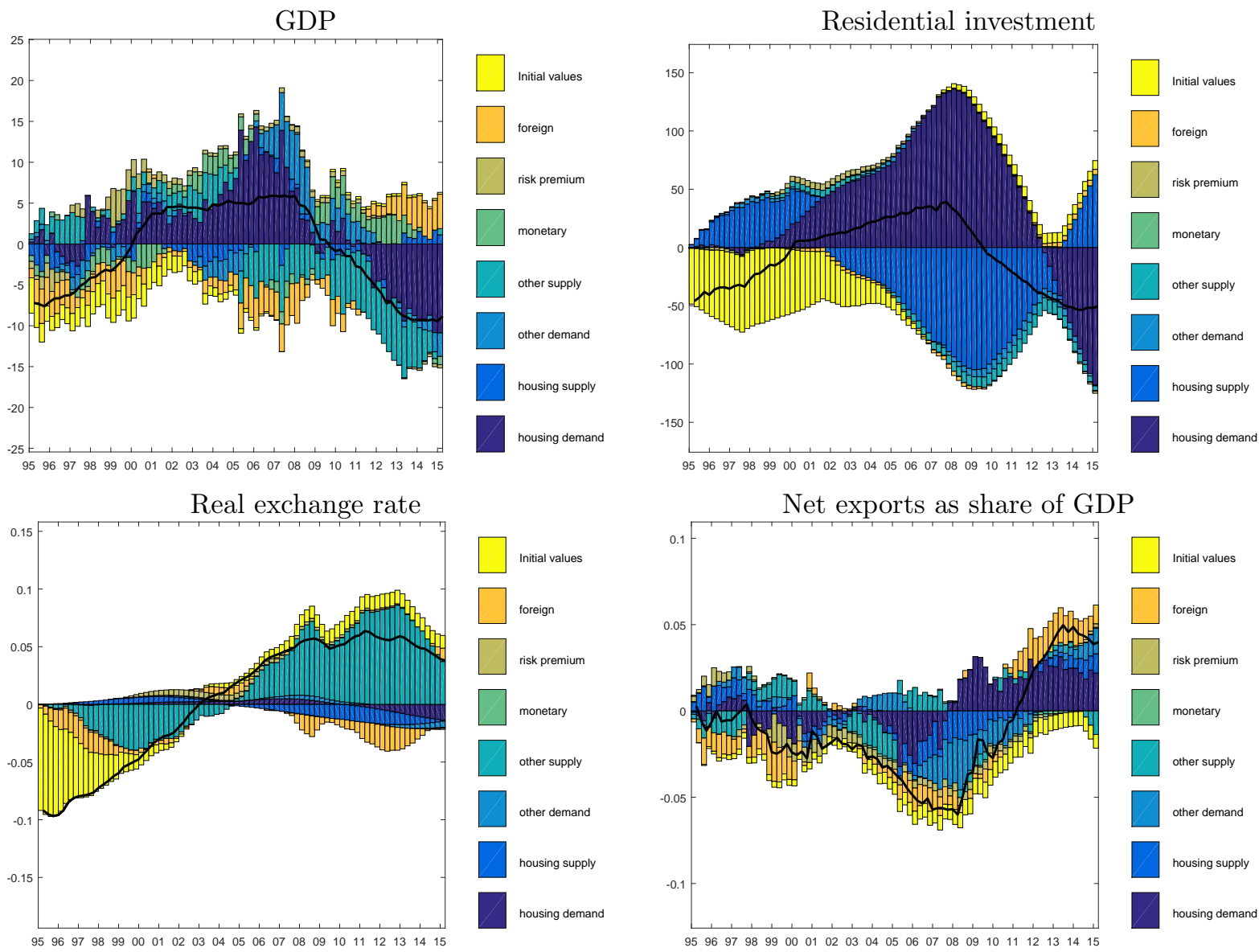

Net exports as share of GDP
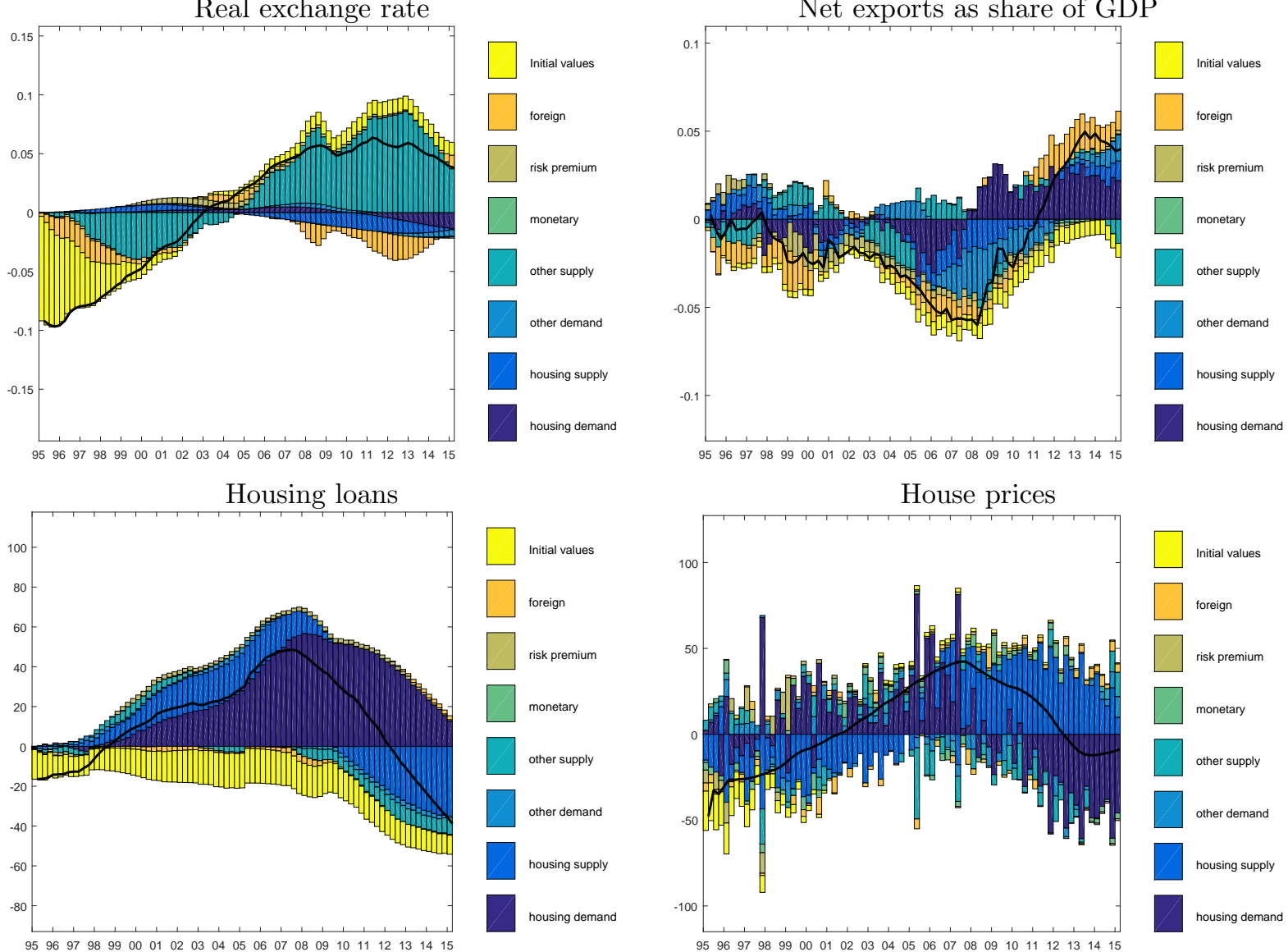

House prices

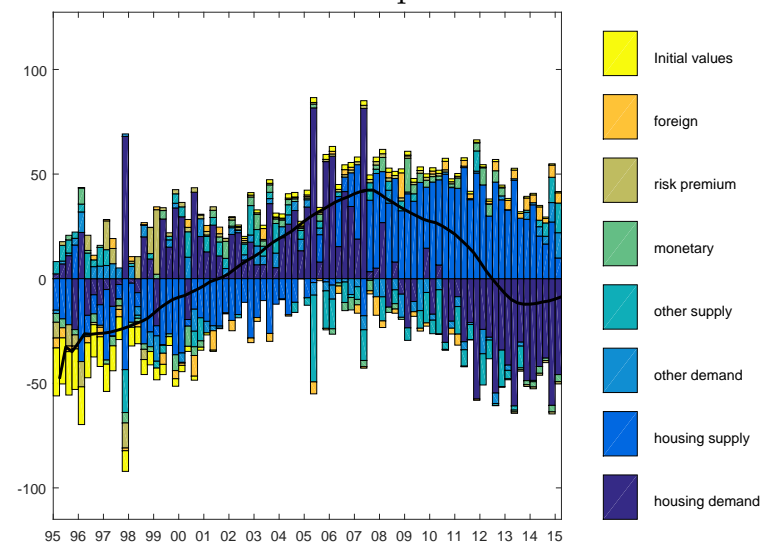

Note: All variables are expressed in percent deviations from steady state, except for net exports as share of GDP, which is in levels. 
Figure 5: Impulse responses to common housing preference shock
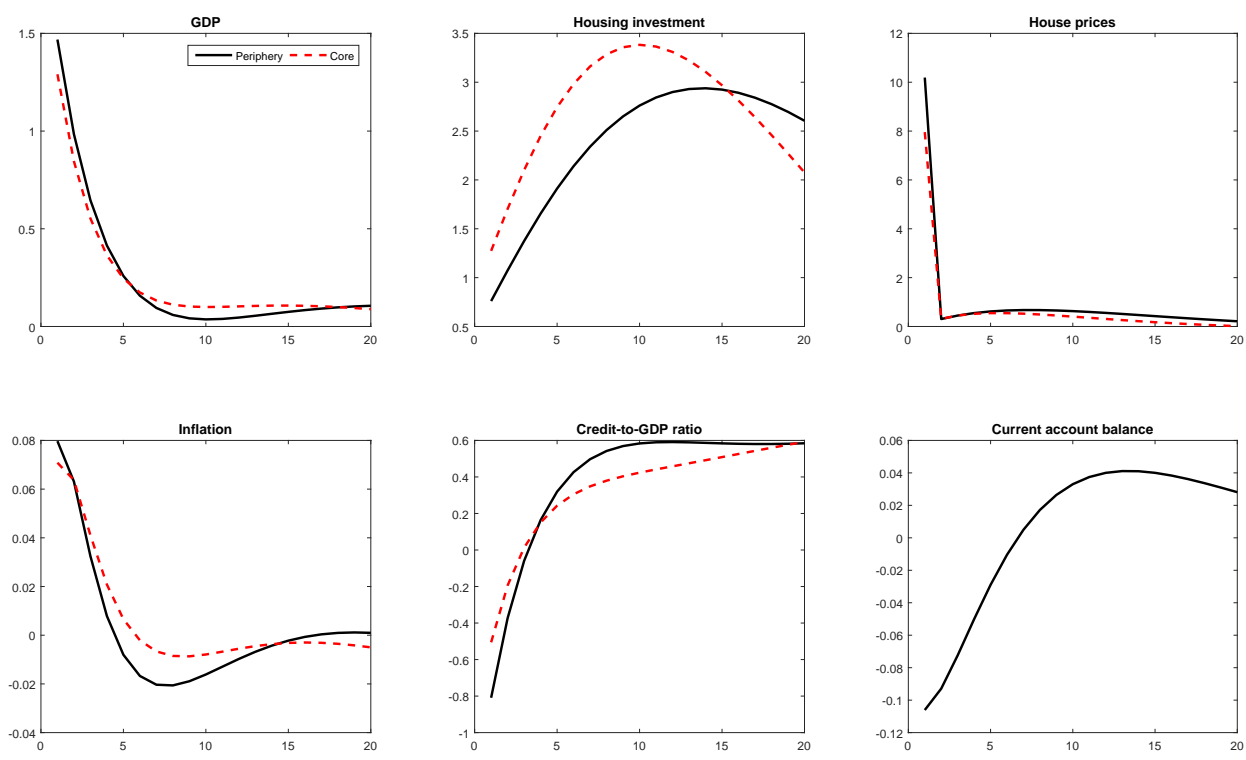

Note: All variables are expressed in percent deviations from the steady state.The credit-to-GDP ratio and inflation are annualized.

Figure 6: Impulse responses to macroprudential policy shocks in the periphery
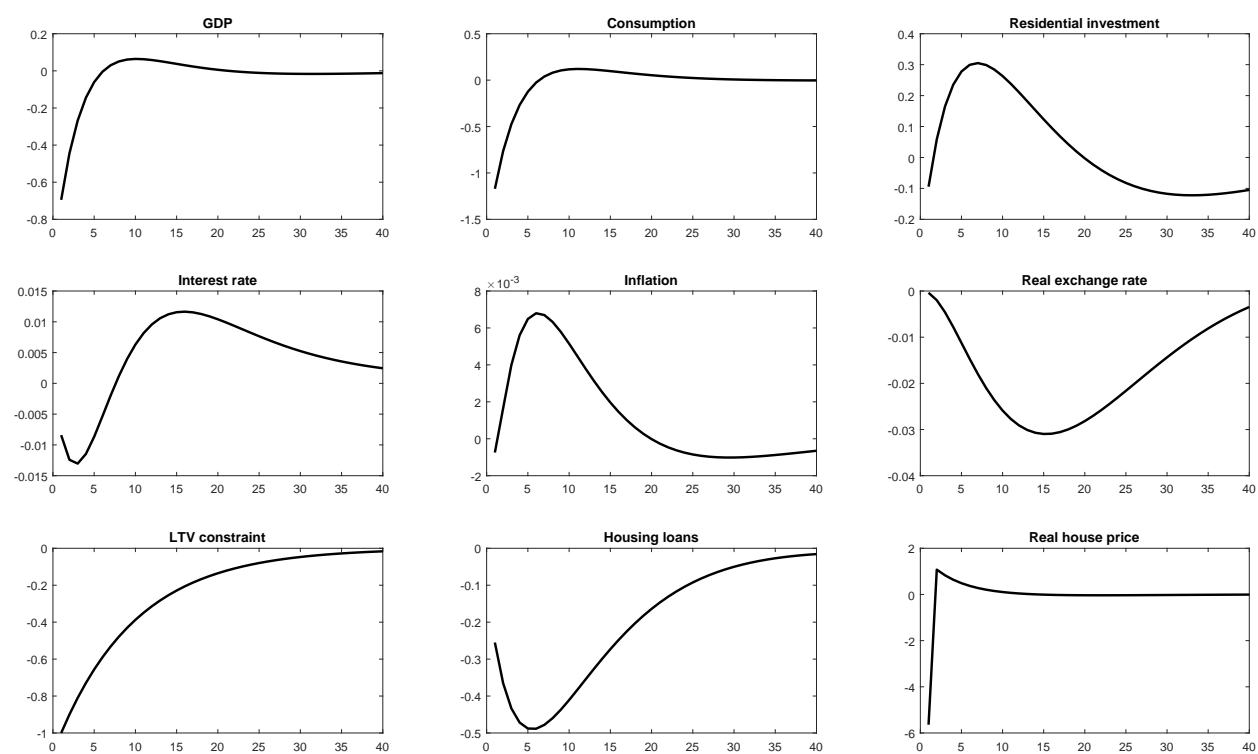

—LTV shock

Note: All variables are expressed in percent deviations from the steady state. The LTV ratio is assumed to follow an AR(1) process with autoregression of 0.9 . 
Figure 7: Impulse responses to monetary policy shocks
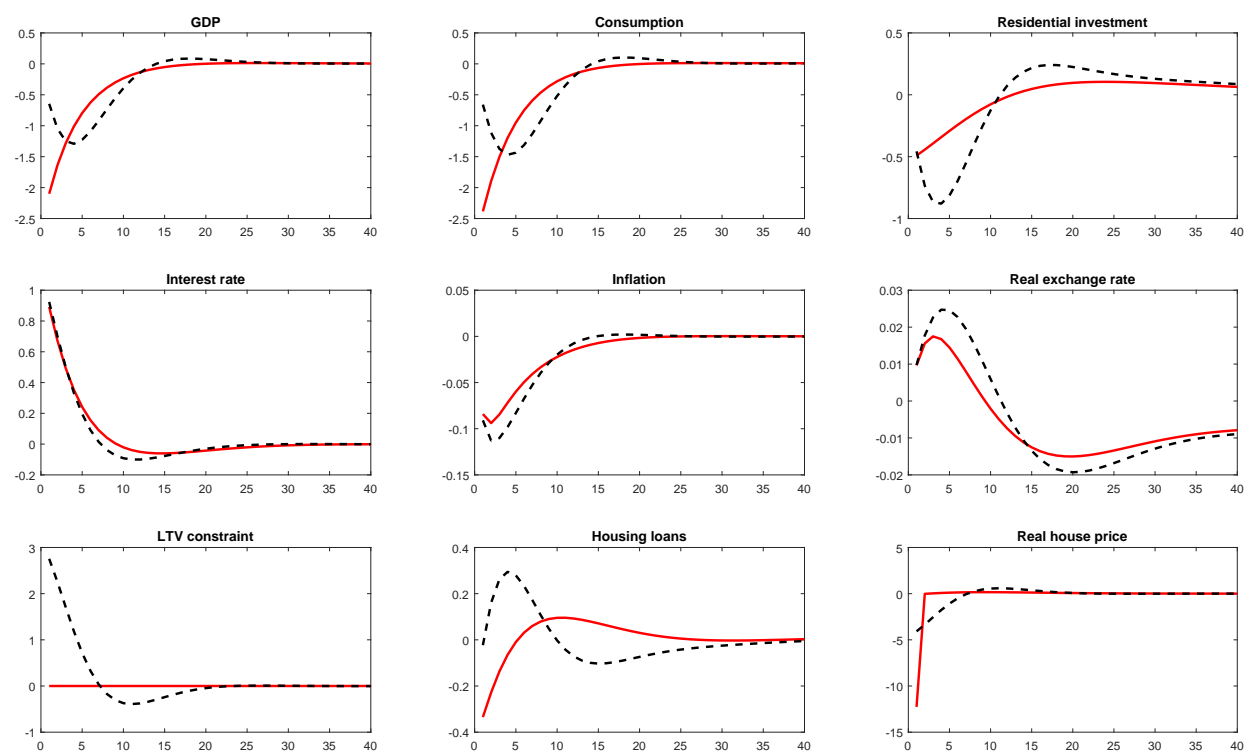

- constant LTV - - active macroprudential

Note: All variables are expressed in percent deviations from the steady state. Macroprudential policy parameters in the active scenario are: $\gamma_{m l}=-0.06, \gamma_{m p}=-0.90, \gamma_{m l}^{*}=-0.06, \gamma_{m p}^{*}=-0.80$.

Figure 8: Historical and counterfactual paths under optimal monetary policy maximizing welfare
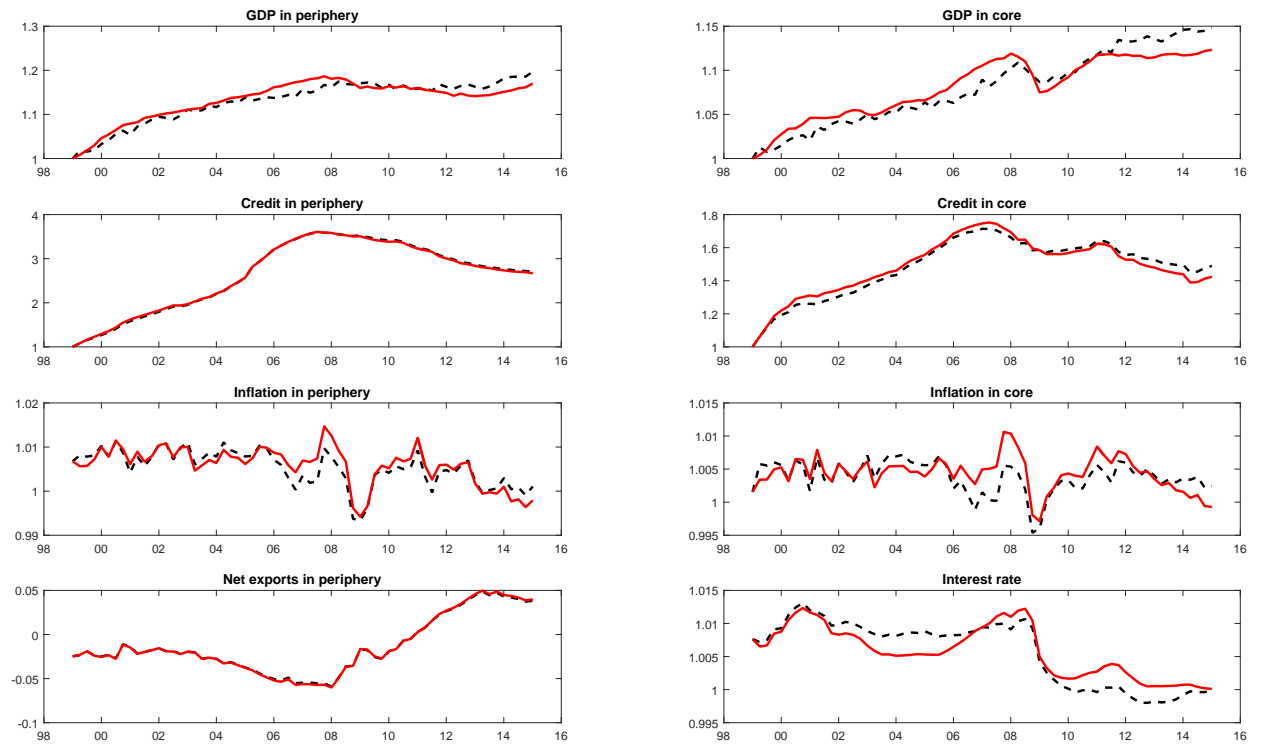

--- countertactual — nistorical

Note: All variables are expressed in levels. Monetary policy parameters in the counterfactual scenario are: $\gamma_{\pi}^{*}=1, \gamma_{y}^{*}=0.36$. 
Figure 9: Historical and counterfactual paths under optimal macroprudential policy maximizing welfare
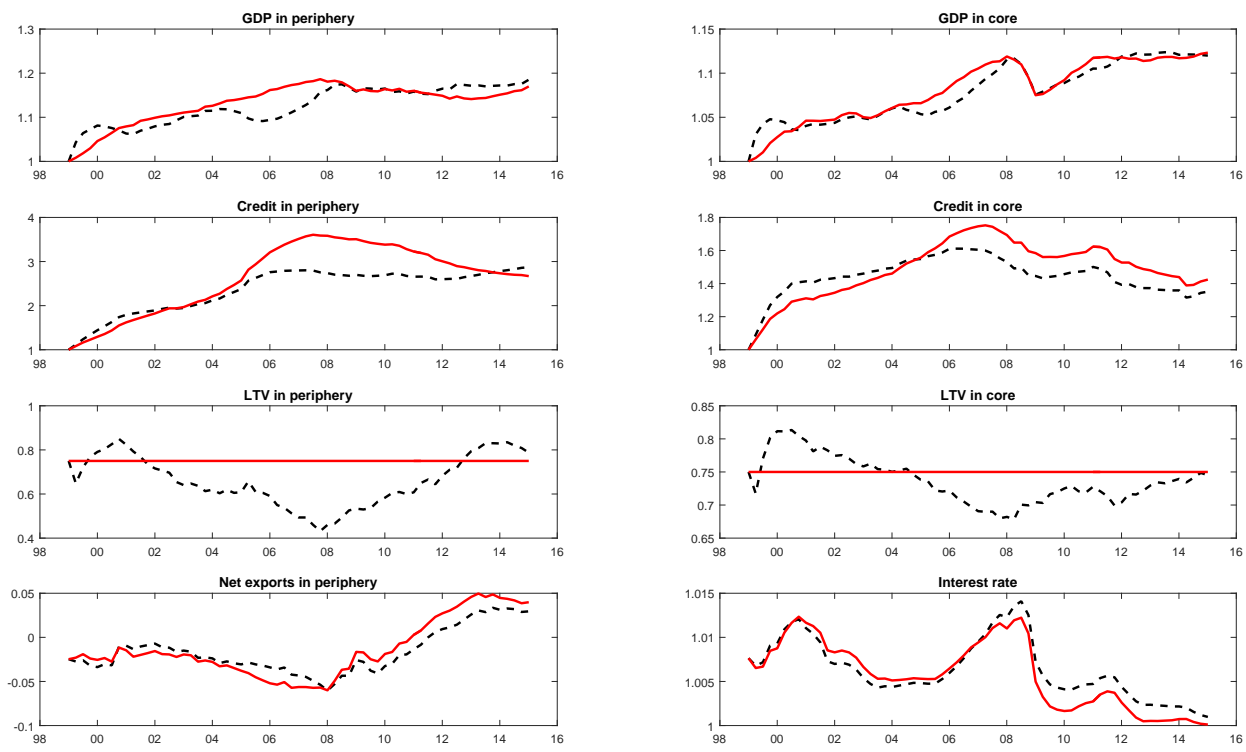

--- countertactual

Note: All variables are expressed in levels. Macroprudential policy parameters in the counterfactual scenario are: $\gamma_{m l}=-0.06, \gamma_{m p}=-0.90, \gamma_{m l}^{*}=-0.06, \gamma_{m p}^{*}=-0.80$.

Figure 10: Historical and counterfactual paths under cooperating optimal monetary and macroprudential policies maximizing welfare
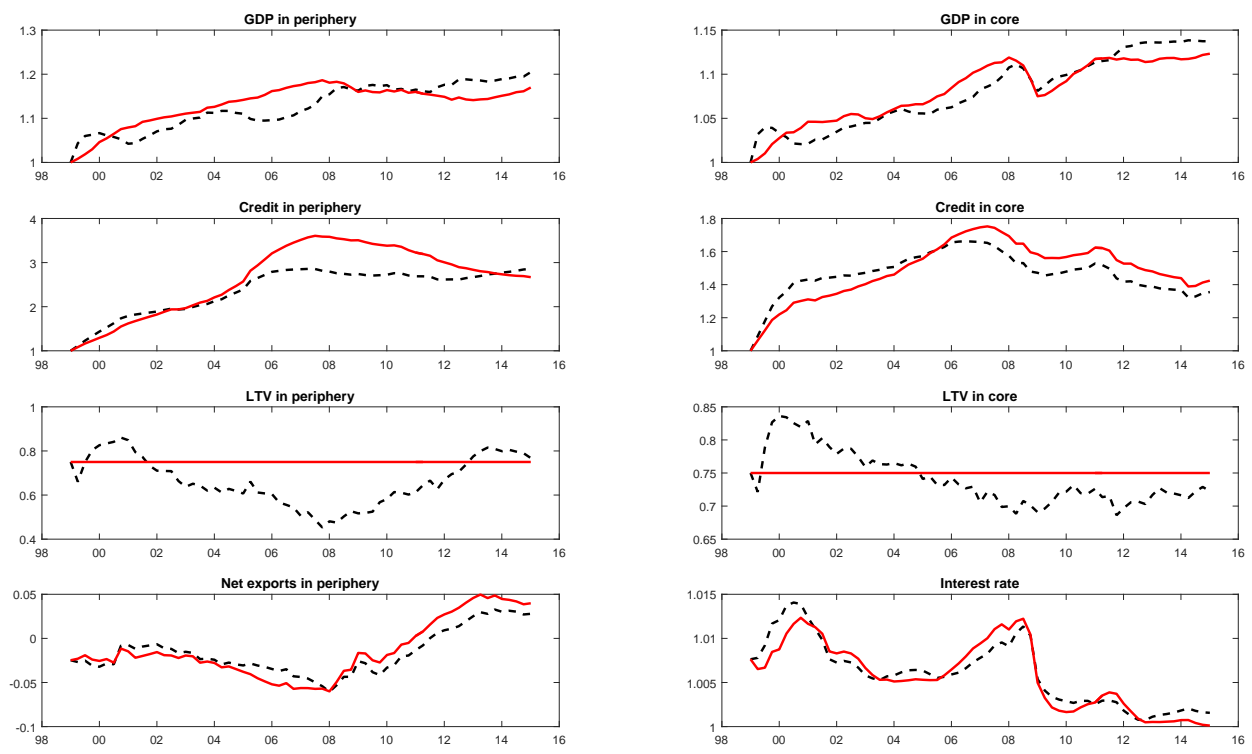

$-\cdots$ - countertactual - historical

Note: All variables are expressed in levels. Monetary policy parameters in the counterfactual scenario are: $\gamma_{\pi}^{*}=1, \gamma_{y}^{*}=0.26$. Macroprudential policy parameters in the counterfactual scenario are: $\gamma_{m l}=-0.05, \gamma_{m p}=-0.85, \gamma_{m l}^{*}=0.00, \gamma_{m p}^{*}=-0.7$. 
Figure 11: Robustness: Historical and counterfactual paths under optimal monetary policy (short sample)
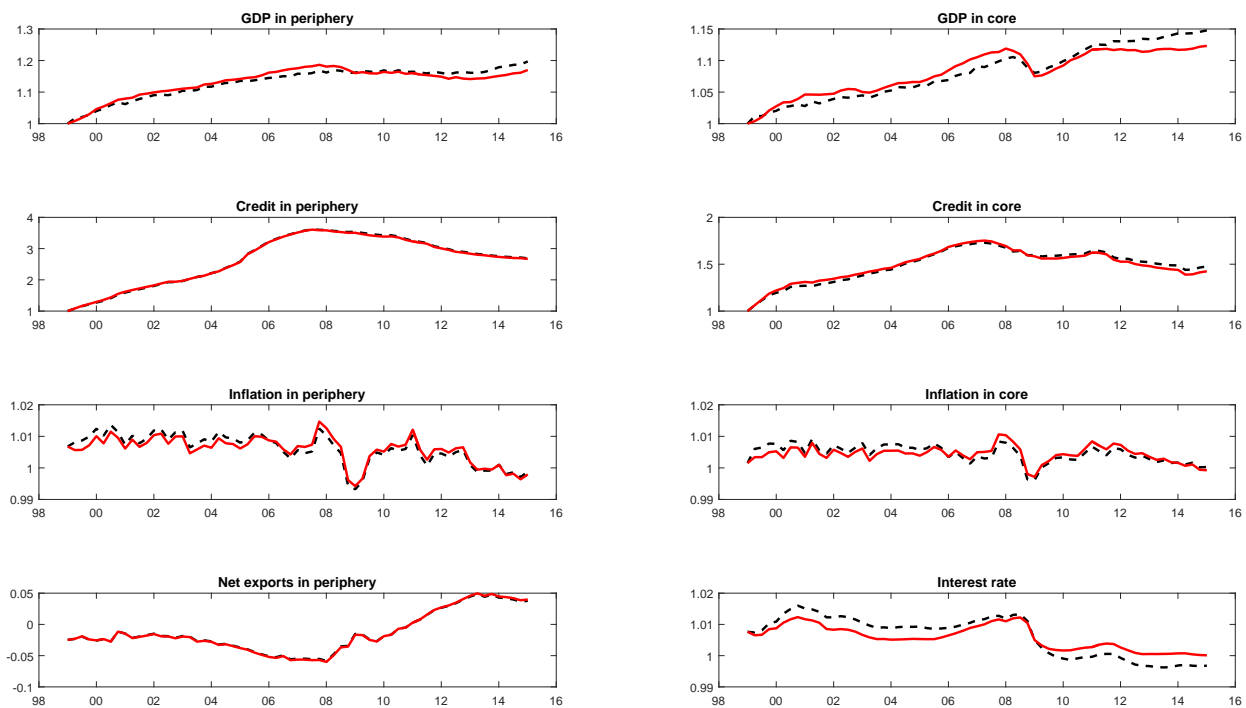

\section{- - - counterfactual — historical}

Note: Results for the variant estimated on shorter sample starting in 1999q1.

Figure 12: Robustness: Historical and counterfactual paths under optimal monetary policy (Italy in periphery)
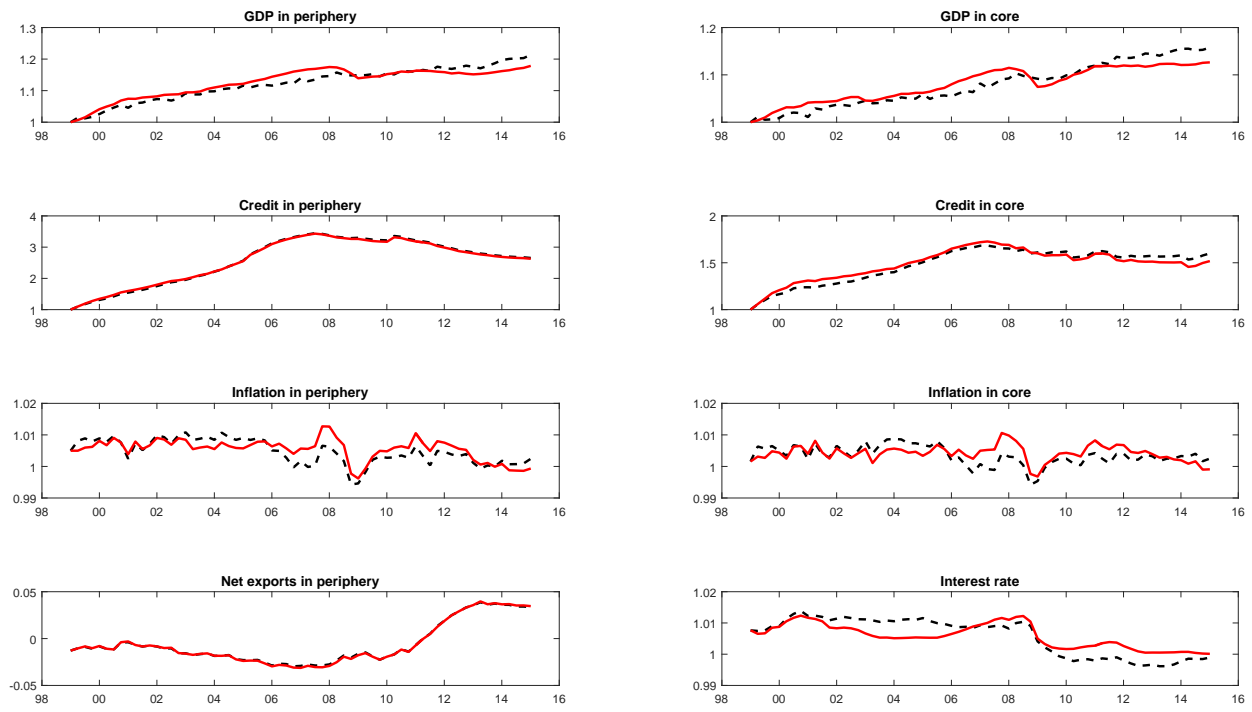

\section{-- counterfactual — historical}

Note: Results for the variant where Italy was included in the periphery group. Slopes for trending variables were not adjusted to facilitate comparison with other variants. 
Figure 13: Robustness: Historical and counterfactual paths under optimal macroprudential policy (short sample)
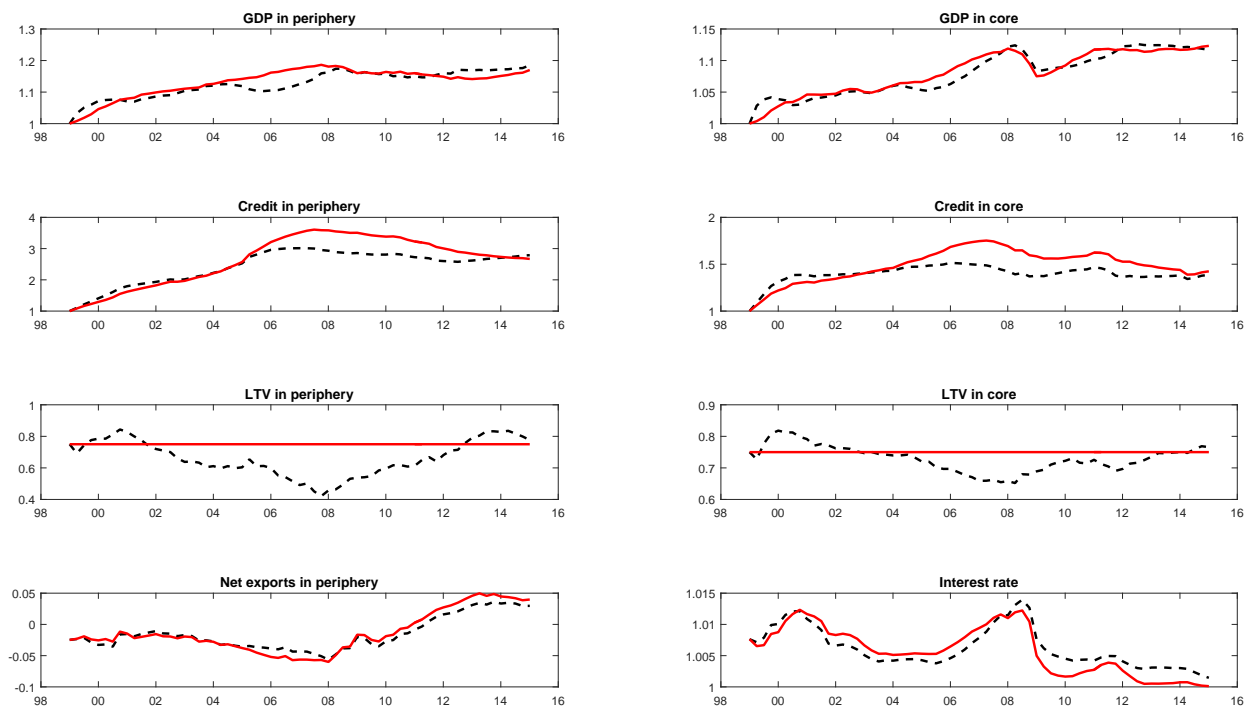

\section{- - - counterfactual — historical}

Note: Results for the variant estimated on shorter sample starting in 1999q1.

Figure 14: Robustness: Historical and counterfactual paths under optimal macroprudential policy (Italy in periphery)
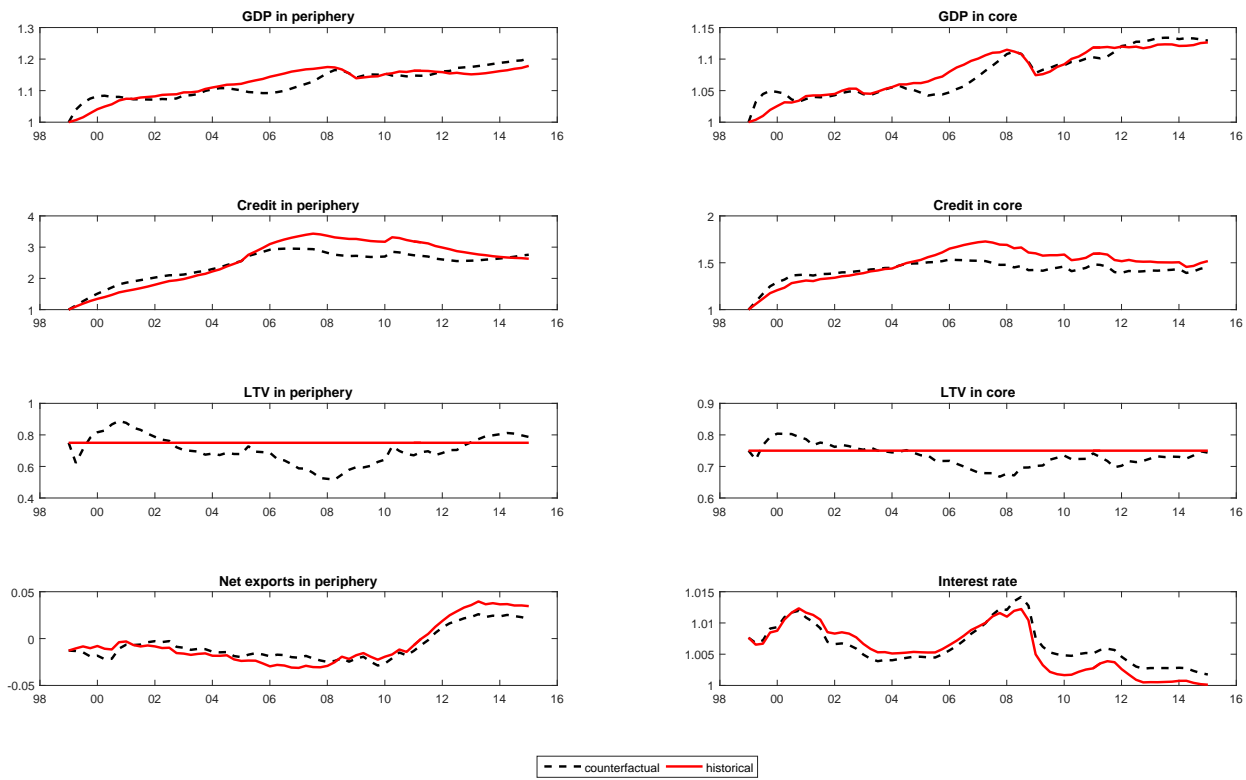

Note: Results for the variant where Italy was included in the periphery group. Slopes for trending variables were not adjusted to facilitate comparison with other variants. 
Figure 15: Robustness: Historical and counterfactual paths under cooperating optimal monetary and macroprudential policies (short sample)
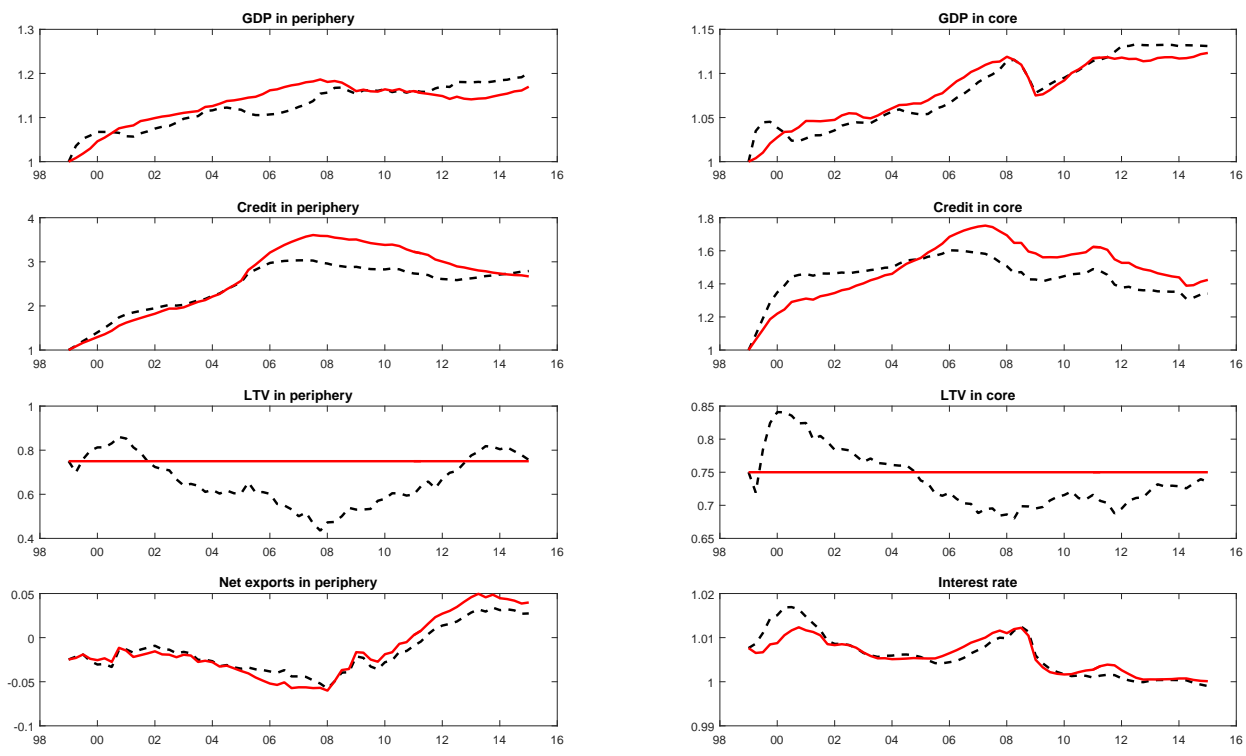

Note: Results for the variant estimated on shorter sample starting in 1999q1.

Figure 16: Robustness: Historical and counterfactual paths under cooperating optimal monetary and macroprudential policies (Italy in periphery)
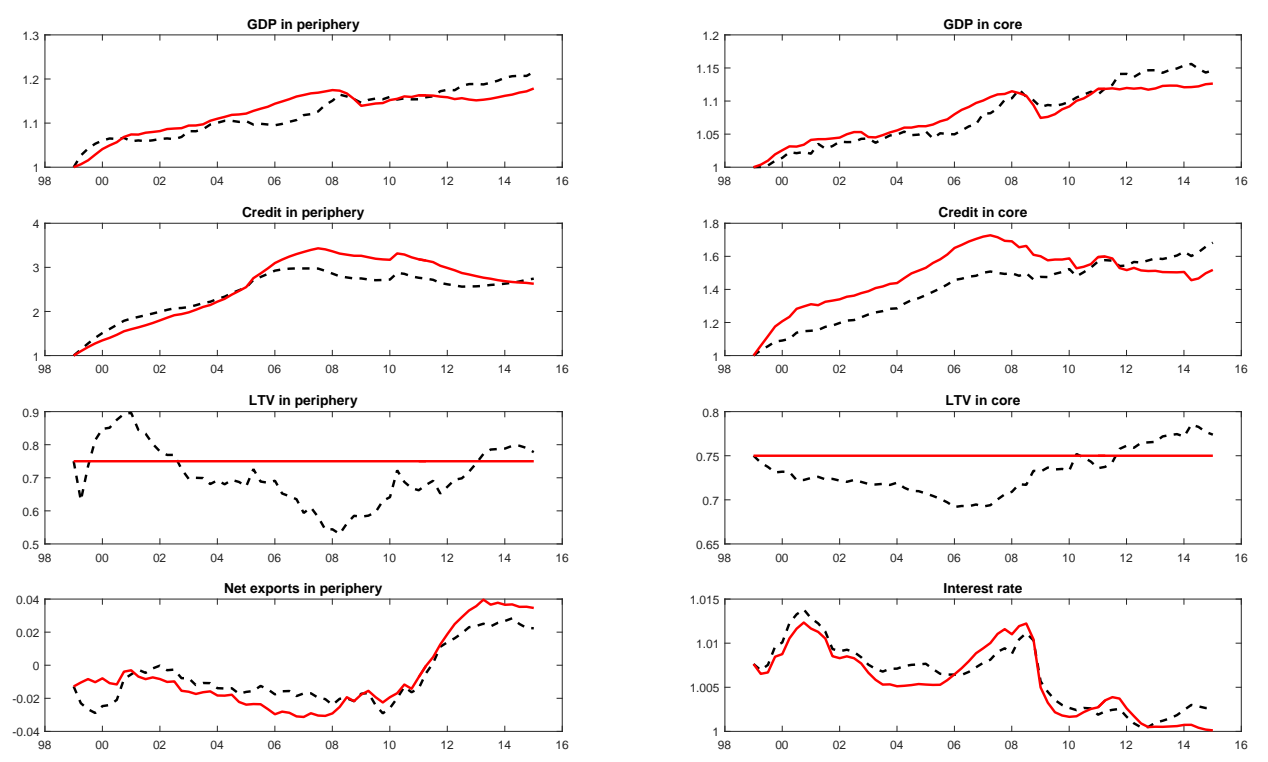

$-\cdots$ - countertactual - historical

Note: Results for the variant where Italy was included in the periphery group. Slopes for trending variables were not adjusted to facilitate comparison with other variants. 